\title{
Arabidopsis ABI5 plays a role in regulating ROS homeostasis by activating CATALASE 1 transcription in seed germination
}

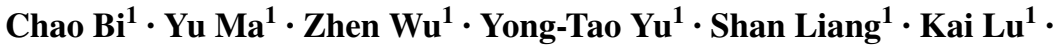 \\ Xiao-Fang Wang ${ }^{1}$
}

Received: 19 July 2016 / Accepted: 13 March 2017 / Published online: 8 April 2017

(C) The Author(s) 2017. This article is an open access publication

\begin{abstract}
It has been known that ABA INSENSITIVE 5 (ABI5) plays a vital role in regulating seed germination. In the present study, we showed that inhibition of the catalase activity with 3-amino-1,2,4-triazole (3-AT) inhibits seed germination of Col-0, abi5 mutants and ABI5-overexpression transgenic lines. Compared with Col-0, the seeds of abi5 mutants showed more sensitive to 3-AT during seed germination, while the seeds of $A B I 5$-overexpression transgenic lines showed more insensitive. $\mathrm{H}_{2} \mathrm{O}_{2}$ showed the same effect on seed germination of Col-0, abi5 mutants and $A B I 5$-overexpression transgenic lines as 3-AT. These results suggest that ROS is involved in the seed germination mediated by ABI5. Further, we observed that T-DNA insertion mutants of the three catalase members in Arabidopsis displayed 3-AT-insensitive or -hypersensitive phenotypes during seed germination, suggesting that these catalase members regulate ROS homeostasis in a highly complex way. ABI5 affects reactive oxygen species (ROS) homeostasis by affecting CATALASE expression and catalase activity. Furthermore, we showed that ABI5 directly binds to the $C A T 1$ promoter and activates $C A T 1$ expression. Genetic evidence supports the idea that CAT1 functions downstream of ABI5 in ROS signaling during seed germination. RNA-sequencing analysis indicates that the transcription of the genes involved in ROS metabolic process or genes responsive to ROS stress is impaired in abi5-1
\end{abstract}

Electronic supplementary material The online version of this article (doi:10.1007/s11103-017-0603-y) contains supplementary material, which is available to authorized users.

Xiao-Fang Wang

wangxf@biomed.tsinghua.edu.cn

1 Center for Plant Biology, School of Life Sciences, Tsinghua University, Beijing 100084, China seeds. Additionally, expression changes in some genes correlative to seed germination were showed due to the change in $A B I 5$ expression under 3-AT treatment. Together, all the findings suggest that $\mathrm{ABI} 5$ regulates seed germination at least partly by affecting ROS homeostasis.

Keywords Arabidopsis thaliana $\cdot$ ABI5 $\cdot$ Catalase $\cdot$ ROS homeostasis $\cdot$ Seed germination
Abbreviations
ABRC Arabidopsis Biological Resource Center
CAT Catalase
ROS Reactive oxygen species
3-AT 3-aminotriazol

\section{Introduction}

Seeds are important for sustainable agriculture production and landscape biodiversity. As the first phase transition in the life cycle of higher plants, seed germination is a complex process affected by many factors. However, molecular mechanisms of seed germination are largely unknown.

Reactive oxygen species (ROS), including superoxide $\left({ }^{\bullet} \mathrm{O}_{2}^{-}\right)$, hydrogen peroxide $\left(\mathrm{H}_{2} \mathrm{O}_{2}\right)$, hydroxyl radical $\left({ }^{\circ} \mathrm{HO}\right)$, and singlet oxygen $\left({ }^{1} \mathrm{O}_{2}\right)$, has been believed to be connected with many biotic and abiotic stress, such as oxidative stress, drought stress, salt stress, and pathogen stress (Dat et al. 2000; Apel and Hirt 2004; Laloi et al. 2004; Torres and Dangl 2005; Miller et al. 2008). New evidence suggests that ROS is not only a cytotoxic molecule, but also emerges as a key regulator in seed physiology where ROS mediates seed germination (Bailly 2004; El-Maarouf-Bouteau et al. 2007; Bailly et al. 2008; Ye et al. 2012). An optimal range of ROS level is required for successful germination. 
Disruption of the ROS homeostasis will reduce the ability of seed germination (Bailly et al. 2008). The balance between ROS production and scavenging should be under elaborate and strict control for seed germination.

$\mathrm{H}_{2} \mathrm{O}_{2}$, a major ROS, is more stable than other ROS and is capable of long-distance diffusion across membranes, which is also admitted as the most likely ROS messenger (Möller and Sweetlove 2010). $\mathrm{H}_{2} \mathrm{O}_{2}$ promotes seed germination (Fontaine et al. 1994; Wang et al. 1998; Ogawa and Iwabuchi 2001) and affects the aleurone programmed cell death (PCD) of cereal grains during germination and seedling establishment (Fath et al. 2001). Arabidopsis catalase (CAT) forms a highly conserved enzyme family consisting of three members, CAT1 (At1g20630), CAT2 (At4g35090) and CAT3 (At1g20620), which are involved in catalyzing the $\mathrm{H}_{2} \mathrm{O}_{2}$ decomposition to water and oxygen (Chevalier et al. 1992; Frugoli et al. 1996). CAT provides the cell with an extremely efficient mechanism of removing $\mathrm{H}_{2} \mathrm{O}_{2}$ because they decompose $\mathrm{H}_{2} \mathrm{O}_{2}$ without consuming the cellular reducing equivalents (Smykowski et al. 2010). These CATALASE genes exhibit different spatial and temporal expression patterns throughout the plant life cycle. Whereas CAT1 is primarily expressed in the reproductive tissues and seeds, CAT2 is strongly expressed in the photosynthetic tissue and CAT3 is ubiquitously expressed, especially in roots and young leaves (Zimmermann et al. 2006; Du et al. 2008; Mhamdi et al. 2010). It has been shown that CAT controls the concentration of ROS in cells (Foyer and Noctor 2000; Mhamdi et al. 2010). CAT activity is also influenced by other factors, such as salicylic acid and nitric oxide (Chen et al. 1993; Durner and Klessing 1996; Clark et al. 2000). Previous studies focused mainly on CAT function in plant leaves, especially in regulating the onset of leaf senescence (Smykowski et al. 2010), but whether CAT regulates seed germination is largely unknown in Arabidopsis .

Abscisic acid is a kind of important stress hormones, which functions in many physiological processes, including seed maturation, seed dormancy, growth and developmental regulation, and response to environmental stresses (Zeevaart and Creelman 1988; Hoffmann-Benning and Kende 1992; Wang et al. 2013). In Arabidopsis, ABSCISIC ACID-INSENSITIVE MUTANT 5 (ABI5), a bZIP transcription factor, plays a vital role in mediating ABA signaling during seed maturation (Finkelstein and Lynch 2000). $\mathrm{ABI} 5$ interacts with $\mathrm{ABA}$ responsive cis-regulatory elements of some genes, such as EMI and EM6 (a class I Late Embryogenesis Abundant protein), to regulate seed maturing and seed germination (Carles et al. 2002).

It has been reported that the maize gene $C A T 1$ promoter contains a G-box or ABA responsive element (ABRE) and antioxidant responsive element (ARE), which indicates the important protective role of CAT in response to oxidative stresses (Polidoros and Scandalios 1999; Guan et al. 2000).
GBF1, a G-box binding factor, is involved in the regulation of CAT2 expression and intracellular $\mathrm{H}_{2} \mathrm{O}_{2}$ content, which directly binds to the $C A T 2$ promoter both in vitro and in vivo (Smykowski et al. 2010). However, the mechanism by which the $C A T 1$ gene transcription is regulated remains unknown so far. Could ABI5, a G-box binding protein, bind to the G-box element of $C A T 1$ promoter and regulate $C A T 1$ expression? Does ABI5 mediate the seed germination partially depending on the ROS signaling? These questions concerning the possible interrelationships between ABI5 and CAT1-mediated ROS signal are of importance but currently remain open.

In the present experiments, we showed that the catalases play a critical role in the ABI5-mediated seed germination regulation, in which $\mathrm{ABI} 5$ regulates $C A T 1$ expression directly. Furthermore, ABI5 regulates seed germination at least partly by affecting ROS homeostasis. These findings help to understand regulatory mechanisms of seed germination mediated by ABI5.

\section{Results}

Compared with Col-0, the seeds of abi5 mutants showed more sensitive to 3-AT during seed germination, while the seeds of $A B I 5$-overexpression transgenic lines showed more insensitive

We assessed the possible role of $\mathrm{H}_{2} \mathrm{O}_{2}$, a major kind of ROS, in ABI5-mediated seed germination in Arabidopsis. 3-amino-1,2,4-triazole (3-AT), a CAT activity inhibitor (Margoliash et al. 1960), affects ROS homeostasis by promoting $\mathrm{H}_{2} \mathrm{O}_{2}$ accumulation. The mutants abi5- 1 and abi57, loss-of-function mutants of $A B I 5$, were used (Finkelstein 1994a, b; Nambara et al. 2002; Tamura et al. 2006; Albertos et al. 2015). When treated by different concentrations of 3-AT, including 3, 5 and $10 \mathrm{mM}$, seed germination rate of the wild-type seeds decreased. Furthermore, with the increasing of the concentration of 3-AT, the inhibition of 3-AT to seed germination were more and more significant. This result showed that 3-AT is a seed germination inhibitor (Fig. 1). In the absence of 3-AT, Col-0, abi5 mutants and ABI5-overexpression lines (ABI5OE), including ABI5OEGFP and ABI5OE-Myc, had the same germination rates. In the presence of 3-AT, we found that compared with Col-0, the seed germination of abi5-1 or abi5-7 was much slower, revealing that abi5-1 and abi5-7 were hypersensitive to 3-AT, but the seed germination of ABI5-overexpression lines, was much faster, revealing that $\mathrm{ABI} 5 \mathrm{OE}$ was insensitive to 3-AT (Fig. 1). Because 3-AT is connected with catalase, we suggested that catalase probably participated in the seed germination mediated by ABI5. 

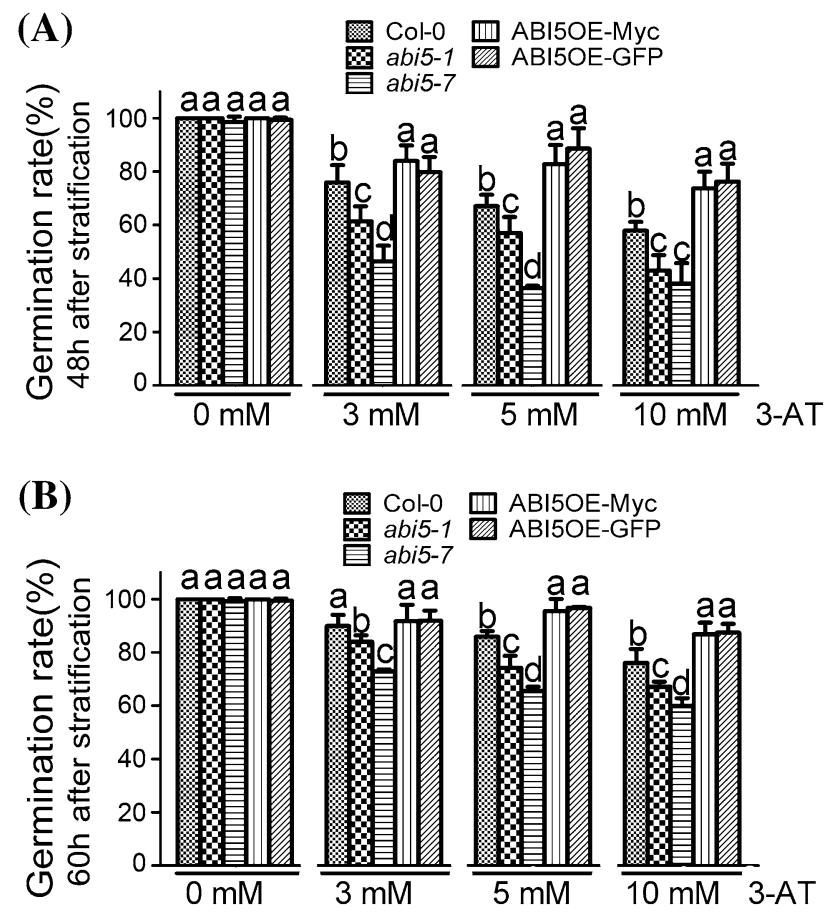

Fig. 1 3-AT affects seed germination mediated by ABI5. Seeds of the wild-type (Col-0), overexpression transgenic lines, including ABI5OE-Myc and ABI5OE-GFP, and ABI5 loss-of-function mutants, including abi5-1 and abi5-7 are grown under light conditions (16-h light/8-h dark) after stratification on MS medium supplemented with $0,3,5,10 \mathrm{mM}$ 3-AT. Germination rates are recorded for $48 \mathrm{~h}$ (a) and $60 \mathrm{~h}(\mathbf{b})$. Each value is the mean \pm SE of at least three independent experiments. Different letters indicate significant differences at $\mathrm{P}<0.05$ (Duncan's multiple range test) when comparing values within the same 3-AT concentration

\section{$\mathrm{H}_{2} \mathrm{O}_{2}$ regulates seed germination mediated by ABI5}

It is well known that catalase is a vital kind of enzymes removing $\mathrm{H}_{2} \mathrm{O}_{2}$. Inhibition of catalase activity by using 3-AT will result in the change in $\mathrm{H}_{2} \mathrm{O}_{2}$ content. So we explored the effect of $\mathrm{H}_{2} \mathrm{O}_{2}$ on seed germination of Col0 , abi5 mutants and $\mathrm{ABI} 5$-overexpression lines. When treated by different concentrations of $\mathrm{H}_{2} \mathrm{O}_{2}$, including 3 , 4 and $5 \mathrm{mM}$, the wild-type seeds showed delayed seed germination, revealing that $\mathrm{H}_{2} \mathrm{O}_{2}$ could inhibit seed germination (Fig. 2). As same as the results of 3-AT treatment, with the increasing of the concentration of $\mathrm{H}_{2} \mathrm{O}_{2}$, the inhibition of $\mathrm{H}_{2} \mathrm{O}_{2}$ to seed germination was more and more significant. In the absence of $\mathrm{H}_{2} \mathrm{O}_{2}$, Col-0, abi5 mutants and $\mathrm{ABI} 5$-overexpression lines, had the same germination rates. In the presence of $\mathrm{H}_{2} \mathrm{O}_{2}$, we found that compared with Col- 0 , the seed germination of abi5-1 or abi5-7 was much slower, revealing that abi5-1 and abi5-7 were hypersensitive to $\mathrm{H}_{2} \mathrm{O}_{2}$. As for ABI5-overexpression lines, we found that seed germination were insensitive to different concentrations of $\mathrm{H}_{2} \mathrm{O}_{2}$ (Fig. 2). These results
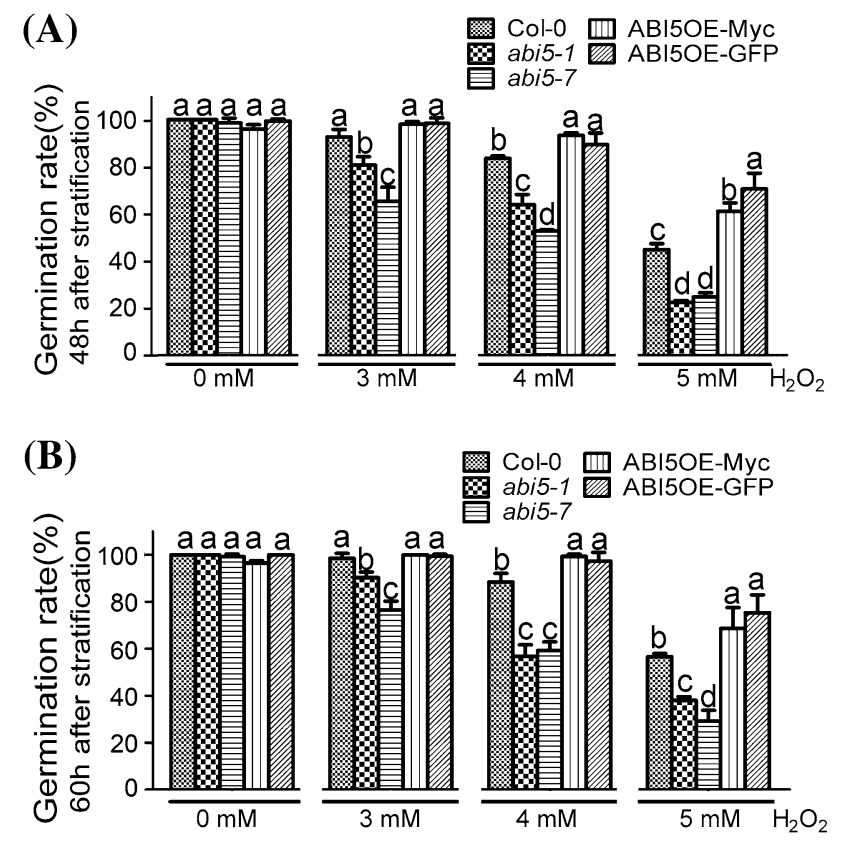

Fig. $2 \mathrm{H}_{2} \mathrm{O}_{2}$ is involved in seed germination mediated by ABI5. Seeds of the wild-type (Col-0), overexpression transgenic lines, including ABI5OE-Myc and ABI5OE-GFP, and ABI5 loss-of-function mutants, including abi5-1 and abi5-7 were grown under light conditions (16-h light/8-h dark) after stratification on MS medium supplemented with $0,3,4,5 \mathrm{mM} \mathrm{H}_{2} \mathrm{O}_{2}$. Germination rates are recorded for $48 \mathrm{~h}$ (a) and $60 \mathrm{~h} \mathrm{(b)}$. Each value is the mean $\pm \mathrm{SE}$ of at least three independent experiments. Different letters indicate significant differences at $\mathrm{P}<0.05$ (Duncan's multiple range test) when comparing values within the same $\mathrm{H}_{2} \mathrm{O}_{2}$ concentration

showed that $\mathrm{H}_{2} \mathrm{O}_{2}$ was involved in the seed germination mediated by ABI5.

\section{CAT mutants show either insensitive or hypersensitive to the catalase activity inhibitor 3-AT}

To furtherly explore the function of catalase in seed germination mediated by ABI5, we examined the phenotypes of catalase members with 3-AT treatment. Considering the composition of CAT family, we identified CAT1, CAT2 and CAT3 mutants from the ABRC stock, including cat 1 1, cat $1-3$, cat $2-2$, cat2-3, cat3-1 and cat3-2 (Fig. 3a). To characterize these mutants, we analyzed the CAT expression using quantitative RT-PCR and protein gel blot analysis. CAT antibodies were used to recognize three CAT members synchronously. Because CAT1 and CAT2, with the high homology and similar molecular weight, appeared in the same band in the protein gel (Hu et al. 2010; Supplementary Fig. S1), we could not distinguish CAT1 and CAT2. RT-PCR results showed that cat1-1, cat1-3, cat31 and cat $3-2$ were knockdown mutants, while cat2-2 and cat2-3 were knockout mutants (Fig. 3b). The protein gel blot analysis showed that there was no obvious change 


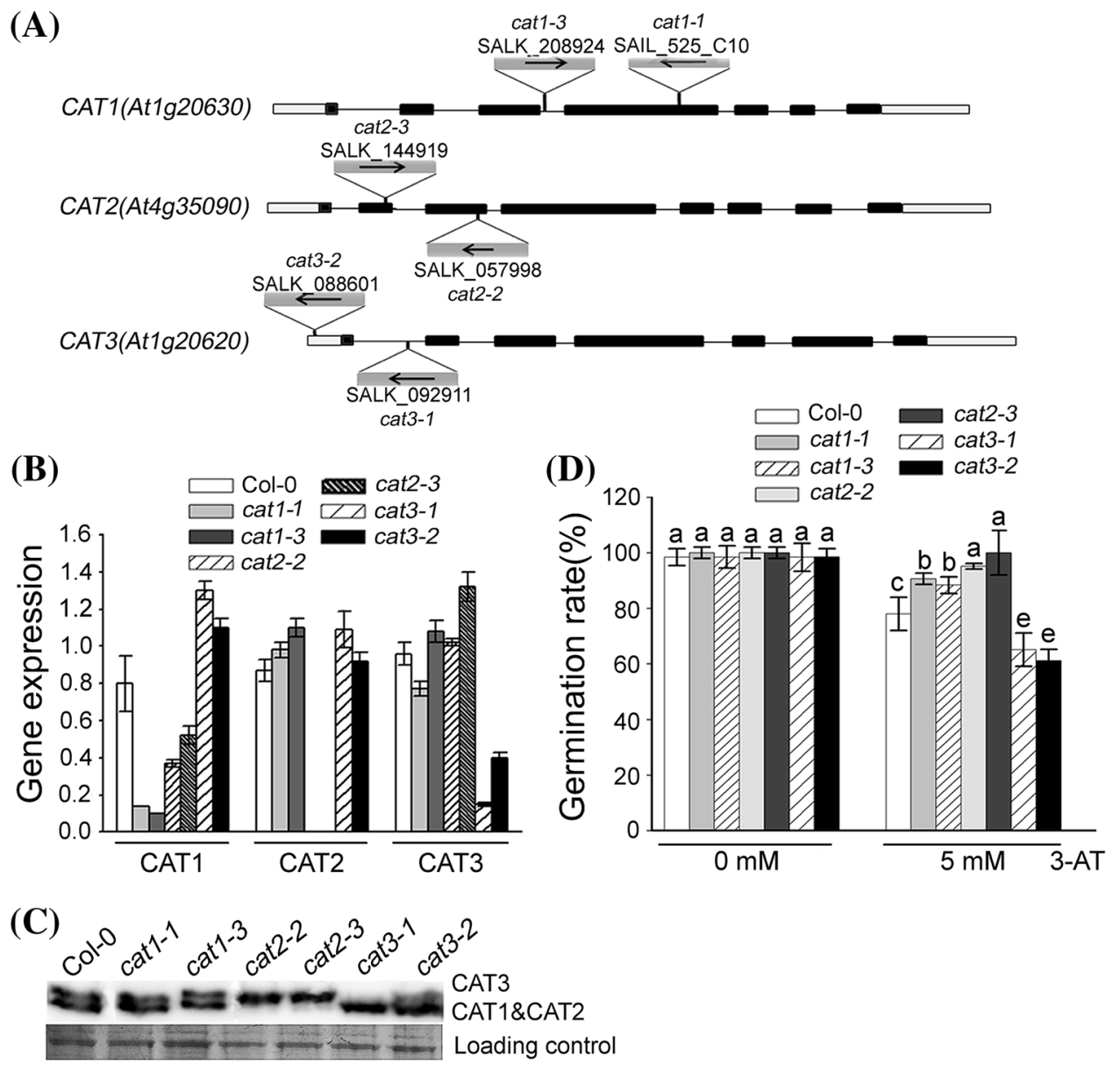

Fig. 3 Molecular and biochemical characterizations of the catalase mutants. a Structures of the CAT1, CAT2 and CAT3 genes are shown with the T-DNA insertion sites in cat1-1 (SAIL_525_C10), cat1-3 (SALK_208924), cat2-2 (SALK_057998), cat2-3 (SALK_144919), cat3-1 (SALK_092911) and cat3-2 (SALK_088601). Exons are indicated by black blocks, introns by solid lines and untranslated regions by grey broken lines. The black arrowhead indicates the orientation of the T-DNA insertion. b Quantitative RT-PCR analysis of CAT gene expressions in wild-type and catalase mutants is shown. Each value for real-time PCR is the mean \pm SE of three independent experiments. c Protein gel blot analysis was performed using anti-catalase serum and total proteins were extracted from seeds grown under 16-h

in CAT protein level in cat1-1 and catl-3 mutant seeds, although $C A T 1$ showed remarkably decrease at RNA level (Fig. 3c). We did not detect the CAT1 and CAT2 proteins in cat2-2 and cat2-3 mutants, but we observed dominant increase of CAT3 expression. In cat3-1 and cat3-2 mutants, the increase of CAT1 and CAT2 expression was remarkable. These indicated that different CAT members had the feedback effect on other member expression.

Although CAT members had different changes in these mutants, we found that they all showed the same germination rate under normal condition. But under $5 \mathrm{mM}$ light/8-h dark conditions for $24 \mathrm{~h}$ after stratification. Protein extracts were stained with Ponceau S as a loading control. The protein gel blot assay was repeated independently three times. $\mathbf{d}$ The effect of 3-AT on seed germination in catalase mutants. Germination rates were recorded for the wild-type, $C A T$ homozygous mutants grown under light conditions ( $16 \mathrm{~h}$ light/8 $\mathrm{h}$ dark) for $60 \mathrm{~h}$ after stratification on MS medium supplemented with $0,5 \mathrm{mM} 3$-AT. Each value is the mean $\pm \mathrm{SE}$ of three independent biological experiments, and different letters indicate significant differences at $\mathrm{P}<0.05$ (Duncan's multiple range test) when comparing values within the same 3-AT concentration

3-AT treatment, these mutants showed different sensitivities to 3-AT. The seed germination rates of cat1-1, cat $1-3$, cat $2-2$ and cat $2-3$ were much higher than that of wild-type seeds, but cat3-1 and cat3-2 seeds had lower germination rates compared with wild-type seeds, revealing that the seed germination of cat1-1, cat 1-3, cat $2-2$ and cat2-3 was insensitive to 3-AT, while the seed germination of cat3-1 and cat3-2 was hypersensitive to 3-AT (Fig. 3d). These different phenotypes of seed germination suggested that CAT members may play different roles in ROS signaling during seed germination. 


\section{Change in $A B I 5$ expression negatively affects CAT protein level, while 3-AT does not affect CAT protein level in the different genotypes}

Because the capacity of catalase decomposing $\mathrm{H}_{2} \mathrm{O}_{2}$ is decided by catalase activities and CAT protein levels, $\mathrm{H}_{2} \mathrm{O}_{2}$ content should be affected by the two factors. Firstly, we checked the expressions of CAT at RNA and protein levels in seeds of wild-type Col-0, abi5-1 and ABI5OE-Myc, respectively. We found that the expression of $C A T 1$ and CAT3 changed significantly at RNA level in abi5-1 seeds without 3-AT treatment (Fig. 4a-c). CAT1 expression was down-regulated, while CAT3 expression was up-regulated. Interestingly, expression of CAT3 also showed up-regulated in ABI5OE-Myc seeds. As for CAT2, there was no obvious changes in abi5-1 and ABI5OE-Myc compared with Col0. 3-AT treatment had the different effect on expression of CAT members in Col-0, abi5- 1 and ABI5OE-Myc. It inhibited $C A T 1$ expression in Col-0 and ABI5OE-Myc, while induced CAT2 expression in Col-0, abi5-1 and ABI5OEMyc, and CAT3 expression in Col-0 and abi5-1. It seemed that the change in $A B I 5$ expression could regulate the expression of CAT members with complicate mechanism.

We also detected CAT proteins in seeds of Col-0, abi51 and ABI5OE-Myc. Compared with Col-0, CAT protein level increased in the seeds of abi5-1, while decreased in the seeds of ABI5OE-Myc without 3-AT treatment (Fig. 4d), indicating that $A B I 5$ mutation affects the CAT protein level. On the other hand, we examined the protein levels of the CAT members under 5mM 3-AT treatment in the seeds of Col-0, abi5-1 and ABI5OE-Myc, and found that 3-AT did not affect the CAT protein levels (Fig. 4d). Here we found that expression changes in CAT members were not synchronous completely between RNA and protein level. For example, compared with Col-0, CAT1 showed down-regulated and CAT2 showed no changes in abi5-1 at RNA level; whereas the sum quantity of CAT1 and CAT2 showed a significant increase at protein level. There should be a complicated mechanism on maintaining the balance of CAT members at post-transcription and translation level.

Although 3-AT had no obvious effects on the expression of CAT members at protein level, the difference of their expressions among Col-0, abi5-1 and ABI5OE-Myc should be responsible for the corresponding phenotypes with 3-AT treatment.

\section{3-AT inhibits catalase activities dependently of ABI5 expression}

It has been reported that 3-AT is a catalase inhibitor, so we assayed catalase activities of different genotypes in the presence or absence of 3-AT. In the absence of 3-AT, catalase activity of abi5-1 seeds was lower than that of Col-0 and ABI5OE-Myc (Fig. 5a, b), but there was no difference of the phenotype in seed germination among them (Figs. 1, 2 ). This suggested that although catalase protein and activity were different in Col-0, abi5-1 and ABI5OE-Myc seeds without 3-AT treatment, these differences were not enough to affect ROS homeostasis which can influence seed germination. Under 3-AT treatment, the catalase activity in Col-0, abi5-1 and ABI5OE-Myc seeds were all obviously inhibited, showing that 3-AT could function as the catalase activity inhibitor (Fig. 5a, b). Furthermore, we found that the inhibition of catalase activity in abi5-1 seeds was the most serious (Fig. 5a, b). We suggested that the most
Fig. 4 Expression analysis of CAT members in the seeds of Col-0, ABI5OE-Myc and abi5-1. The seeds of Col-0, ABI5OE-Myc and abi5-1 were grown under 16-h light/8-h dark conditions for $24 \mathrm{~h}$ after stratification on MS medium supplemented with 0 or $5 \mathrm{mM} 3$-AT. a-c are quantitative RT-PCR analysis of $C A T 1$ (A), CAT2 (B) and $C A T 3(\mathrm{C})$, respectively. Each value is the mean \pm SE of three independent experiments. d Protein gel blot analysis of the expression of CAT in the seeds of Col-0, ABI5OE-Myc and abi5-1. Protein extracts were stained with the Ponceau $\mathrm{S}$ as a loading control. The assay was independently repeated three times
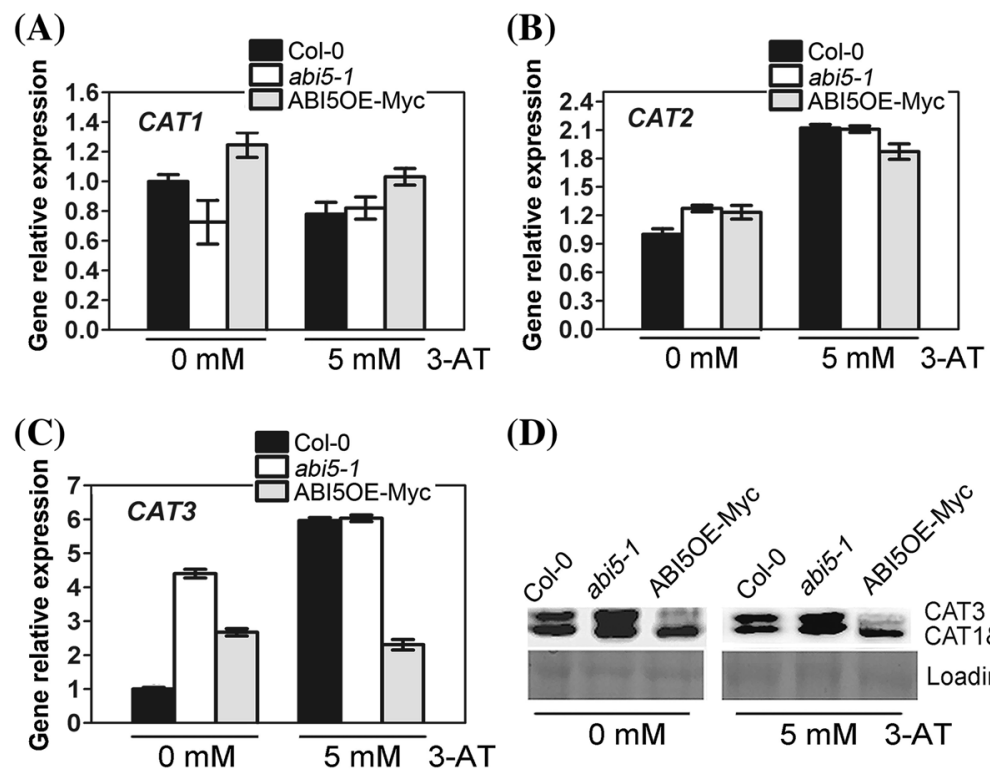

(D)

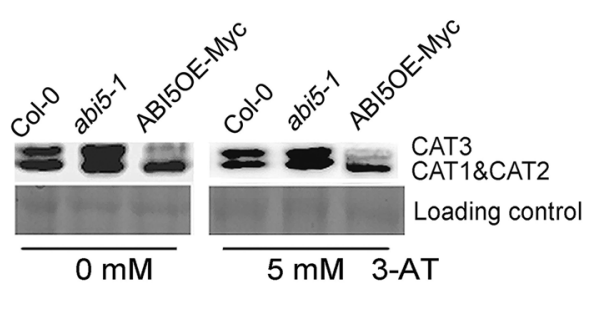



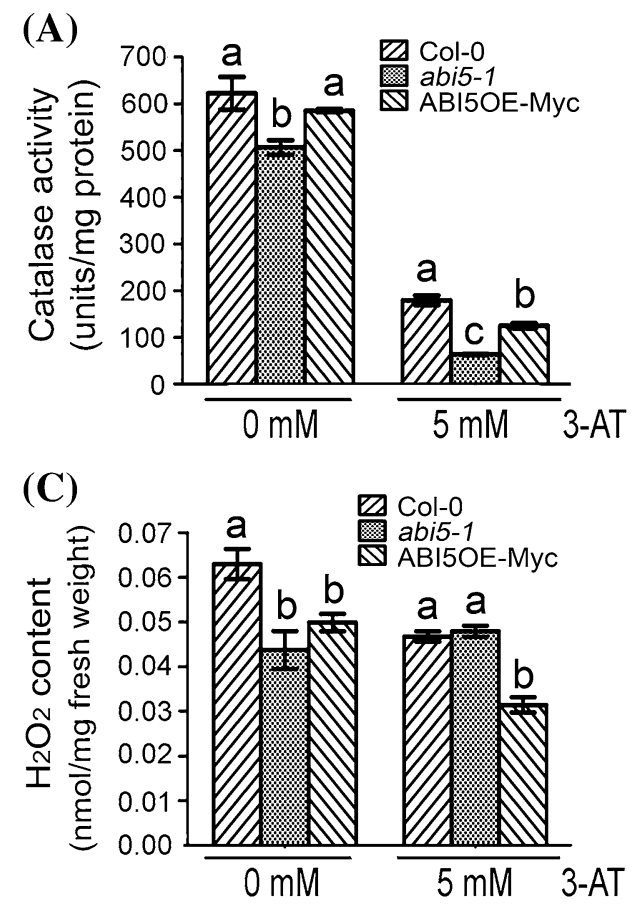

Fig. 5 Changes in catalase activity and $\mathrm{H}_{2} \mathrm{O}_{2}$ content in seeds of Col0 , ABI5OE-Myc and abi5-1. a Measurement of the absolute catalase activity in seeds of Col-0, ABI5OE-Myc and abi5-1 with or without $5 \mathrm{mM}$ 3-AT treatment grown under 16-h light/8-h dark conditions for $24 \mathrm{~h}$ after stratification. Each value is the mean $\pm \mathrm{SE}$ of three independent biological experiments, and different letters indicate significant differences at $\mathrm{P}<0.05$ (Duncan's multiple range test) when comparing values within the same 3-AT concentration. $\mathbf{b}$ Analysis of the relative change in catalase activity in seeds of Col-0, ABI5OE-Myc and abi5-1. The vertical axis represents the relative change in the absolute value of catalase activity in Col-0, ABI5OE-Myc and abi51 seeds in the presence of $5 \mathrm{mM} 3$-AT treatment in relative to that in the absence of 3-AT, respectively. The absolute values of catalase activity in the seeds of Col-0, ABI5OE-Myc and abi5-1 without 3-AT treatment are taken as a control (100\%), respectively. Each value is the mean $\pm \mathrm{SE}$ of three independent biological experiments, and different letters indicate significant differences at $\mathrm{P}<0.05$ (Duncan's multiple range test) when comparing values within the same 3-AT

serious inhibition of catalase activity was connected with the postponed germination of abi5-1 seeds.

\section{3-AT affects $\mathrm{H}_{2} \mathrm{O}_{2}$ content in seeds of wild-type, abi5-1 and ABI5OE-Myc plants in a different way}

The capacity of catalase scavenging $\mathrm{H}_{2} \mathrm{O}_{2}$ is correlated with the catalase protein and catalase activity, which codetermine the $\mathrm{H}_{2} \mathrm{O}_{2}$ content. The lower catalase activity can induce $\mathrm{H}_{2} \mathrm{O}_{2}$ accumulation, and higher CAT protein accumulation can promote $\mathrm{H}_{2} \mathrm{O}_{2}$ decomposition. The final $\mathrm{H}_{2} \mathrm{O}_{2}$ content should be decided by which effect was dominant. We measured $\mathrm{H}_{2} \mathrm{O}_{2}$ content in seeds of Col-0, abi5-1 and ABI5OE-Myc. Without 3-AT treatment, $\mathrm{H}_{2} \mathrm{O}_{2}$ content in both abi5-1 and ABI5OE-Myc seeds were lower than that
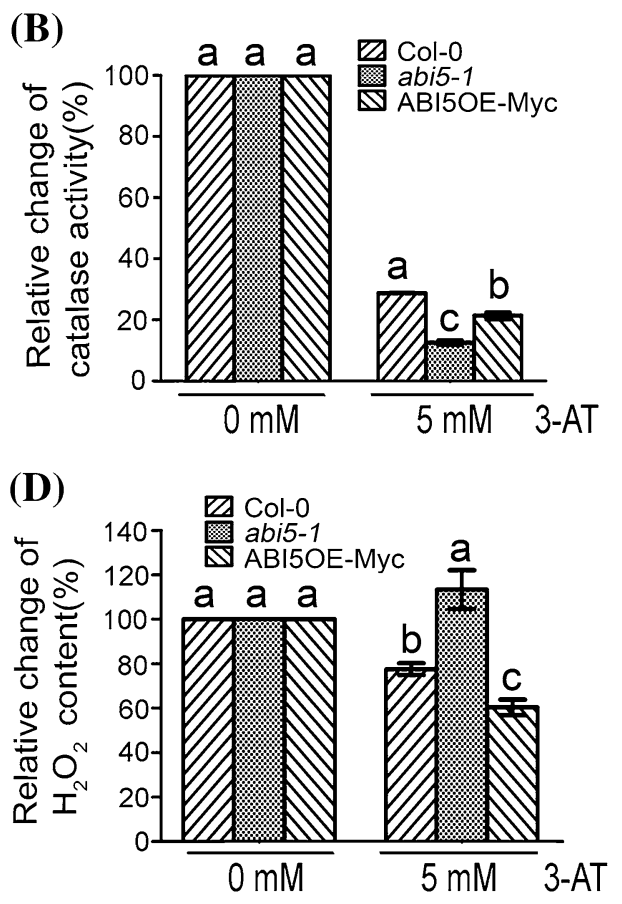

concentration. c Measurement of the absolute $\mathrm{H}_{2} \mathrm{O}_{2}$ content in seeds of Col-0, ABI5OE-Myc and abi5-1 with or without $5 \mathrm{mM} 3$-AT treatment grown under 16-h light/8-h dark conditions for $24 \mathrm{~h}$ after stratification. Each value is the mean $\pm \mathrm{SE}$ of three independent biological experiments, and different letters indicate significant differences at $\mathrm{P}<0.05$ (Duncan's multiple range test) when comparing values within the same 3-AT concentration. $\mathbf{d}$ Analysis of the relative change in the $\mathrm{H}_{2} \mathrm{O}_{2}$ content in seeds of Col-0, ABI5OE-Myc and abi5-1. The vertical axis represents the relative change in $\mathrm{H}_{2} \mathrm{O}_{2}$ content of the absolute value of $\mathrm{H}_{2} \mathrm{O}_{2}$ content of Col-0, ABI5OE-Myc and abi5-1 with $5 \mathrm{mM}$ 3-AT treatment in relative to that without $5 \mathrm{mM}$ 3-AT treatment, respectively. The absolute values of $\mathrm{H}_{2} \mathrm{O}_{2}$ content in the seeds of Col-0, ABI5OE-Myc and abi5-1 without 3-AT treatment are taken as a control (100\%), respectively. Each value is the mean $\pm \mathrm{SE}$ of three independent biological experiments, and different letters indicate significant differences at $\mathrm{P}<0.05$ (Duncan's multiple range test) when comparing values within the same 3-AT concentration

in Col-0 seeds (Fig. 5c, d). Although the fundamental $\mathrm{H}_{2} \mathrm{O}_{2}$ content was different in Col-0, abi5-1 and ABI5OE-Myc seeds in the absence of 3-AT, the difference did not influence seed germination (Figs. 1, 2). When using 3-AT treatment, the CAT protein level was not influenced, but the catalase activity was inhibited obviously. We conjectured that there would be $\mathrm{H}_{2} \mathrm{O}_{2}$ accumulation in the seeds of Col0, abi5-1 and ABI5OE-Myc. Actually the result showed that except for abi5-1, which showed $\mathrm{H}_{2} \mathrm{O}_{2}$ accumulation, both Col-0 and ABI5OE-Myc showed $\mathrm{H}_{2} \mathrm{O}_{2}$ decrease in the presence of 3-AT (Fig. 5c, d). Furthermore, in comparison to the control panels without 3-AT treatment respectively, we found that $\mathrm{H}_{2} \mathrm{O}_{2}$ content in the seeds of abi5-1 accumulated obviously with 3-AT treatment, while $\mathrm{H}_{2} \mathrm{O}_{2}$ content decreased in the seeds of Col-0 and ABI5OE-Myc. The 
relative decrease of $\mathrm{H}_{2} \mathrm{O}_{2}$ content in ABI5OE-Myc seeds was more remarkable than that in Col-0 seeds (Fig. 5c, d). So we suggested that the relative changes in $\mathrm{H}_{2} \mathrm{O}_{2}$ content with 3-AT treatment were connected with the different phenotypes of seed germination in Col-0, abi5-1 and ABI5OE-Myc.

\section{ABI5 binds to the promoter of CAT1}

How does ABI5 affect ROS homeostasis? Previous studies have demonstrated that $\mathrm{ABI} 5$ is a versatile transcription factor, binding to the G-box (ACGT) motif to promote the expression of EMI and EM6 (Carles et al. 2002). Using PlantCARE (http://bioinformatics.psb.ugent.be/webtools/ plantcare/html/) to analyze the sequence of AtCAT1 promoter, we found two G-box elements within the $442 \mathrm{bp}$ sequence upstream of the AtCATI start codon. Combined with previous evidence on that $C A T 1$ expression was downregulated in abi5-1 at RNA level (Fig. 4a), we were interested in whether ABI5 could affect ROS homeostasis by regulating $C A T 1$ transcription. We detected interaction of the ABI5 with the promoter of CATl in a yeast one-hybrid system. Yeast cells which were co-transformed with both a ABI5-encoding cDNA and CAT1 promoter could grow in a selection SD medium (lacking Trp, Leu and His nutrients, and containing 3-AT), indicating a potential interaction between the ABI5 and CAT1 promoter (Fig. 6a). As a negative control, yeast cell which were co-transformed with both control vector (p53) and CAT2 promoter could not grow in this medium (Fig. 6a). These data suggested that ABI5 could potentially bind to the promoter of $C A T 1$ (Fig. 6a).

To investigate whether ABI5 could directly regulate $C A T 1$ expression, we used electrophoretic gel mobility shift assay (EMSA) with the purified recombinant ABI5 protein. The full length ABI5 protein was overexpressed with a C-terminal 6 residue histidine fusion in E. coli. Most of the recombinant proteins were expressed in the soluble fraction and purified by nickel ion chelate chromatography. We analyzed the $C A T 1$ promoter described in Fig. $6 \mathrm{~b}$ and found two G-box in its promoter region. The probe fragment of pCAT1, which is 189 bp long (-296/-108) and contains two G-box, named box1 and box2, was chosen (Fig. 6b). The mutant probe fragments included box 1 mutation and box 2 mutation, respectively. The EMSA results indicated that ABI5 binds specially to the pCAT1 probe. Both box 1 mutation and box 2 mutation could weaken the binding between ABI5 protein and CATI promoter (Fig. 6c).

Furtherly, we assayed the interaction of ABI5 with the same CATI promoter fragment as EMSA assay by ChIP analysis combined with quantitative real-time PCR. We observed that ABI5 can bind the CAT1 promoter (Fig. 6d). This result was consistent with the result of the above-described EMSA assay (Fig. 6c), and revealed that ABI5 can interact with the CAT1 promoter in vivo.

\section{ABI5 activates $C A T 1$ transcription in vivo}

The evidence from yeast one-hybrid, EMSA and ChIP analysis indicated that ABI5 could bind to the $C A T 1$ promoter. Thus in vivo luciferase complementation imaging assay (LCI) was employed to investigate whether ABI5 could active $C A T 1$ expression in vivo. By analyzing the promoter sequences, the reporter plasmid Pro-CAT1-LUC and the effector plasmid pCAMBIA-ABI5-Myc were constructed separately. When Pro-CAT1-LUC was transfected into the $N$. benthamiana tobacco leaves together with pCAMBIAABI5-Myc, strongly LUC activity was detected (Fig. 6e, f). However, when the pCAMBIA-ABI5-Myc was substituted by the equal amount of pCAMBIA-GFP or pCAMBIAGUS control vector, the LUC activity decreased obviously (Fig. 6e, f). These results revealed that ABI5 can active CATl transcription in vivo.

\section{The CAT1 mutation suppresses 3-AT-hypersensitive phenotype of the loss-of-function mutant abi5-1 in seed germination}

Above evidence had showed that ABI5 can bind to the promoter of $C A T 1$ and active its transcription (Fig. 6). Subsequently, we explored the genetic function of CAT1 in ROS signaling mediated by ABI5. As shown in Figs. 1, 3d, abi5 mutants showed hypersensitive to 3-AT during seed germination, while cat1 mutants showed insensitive to 3-AT. So we suggested that ABI5 and CAT1 played opposite roles in seed germination, respectively. Based on above reason, we generated double mutants of catl-1abi5-1 by crossing. When cat 1 mutation was introduced into abi5-1 mutant, the hypersensitive phenotype in seed germination of abi51 was recovered (Fig. 7). These data provided the genetic evidence that CAT1, as a direct target of ABI5, functioned downstream of ABI5 in ROS signaling. Besides, we also noticed that cat1-1 abi5-1 did not show the same phenotype as cat1-1 did under 3-AT treatment, which meant that CAT1 mutation could not completely block the pathway mediated by ABI5, we suggested that CAT1 was one of the targets of ABI5 during seed germination regulated by ROS.

\section{Disruption of $A B I 5$ alters the expression of genes related to ROS metabolism and ROS signaling in seed germination}

To further confirm that ABI5 functioned as a ROS regulator during seed germination, we analyzed the effect of the abi5 mutation on the expression of ROS-responsive genes in seed germination. Total RNAs were extracted from 

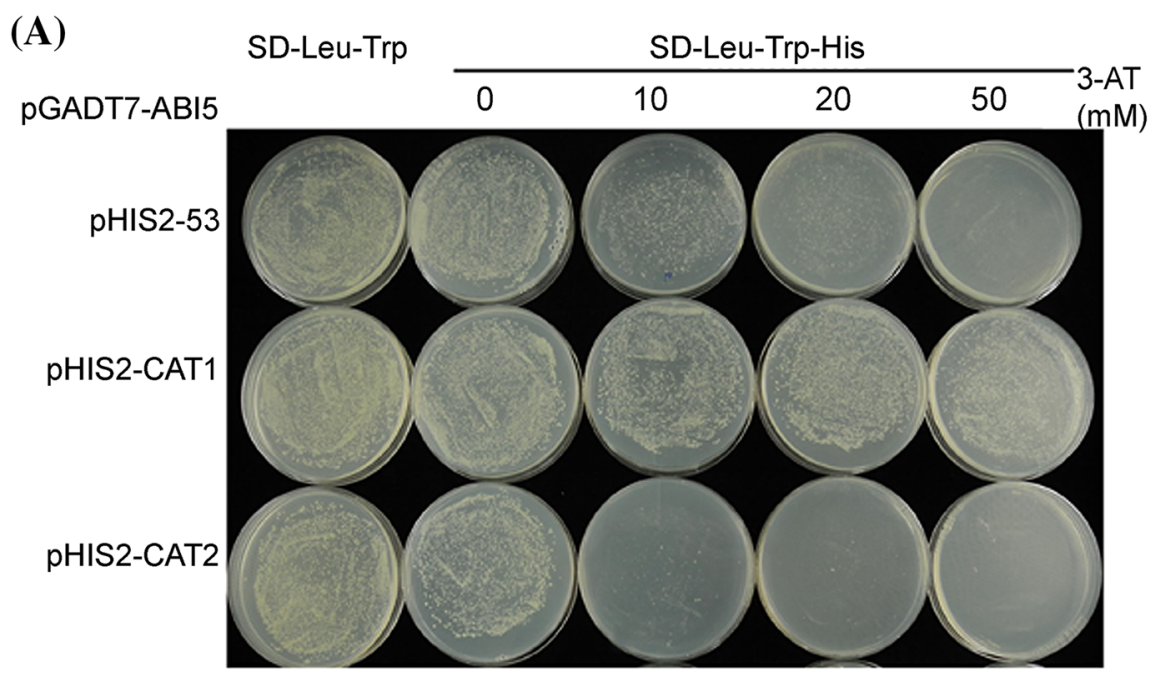

(B)

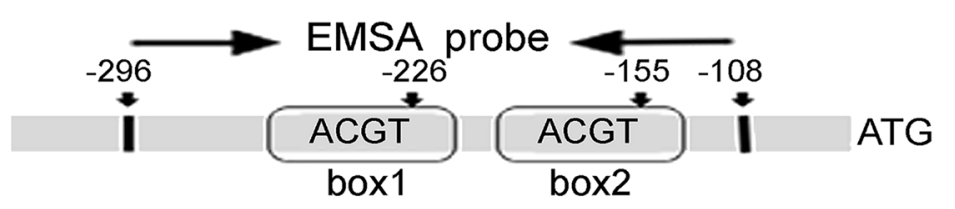

(C)

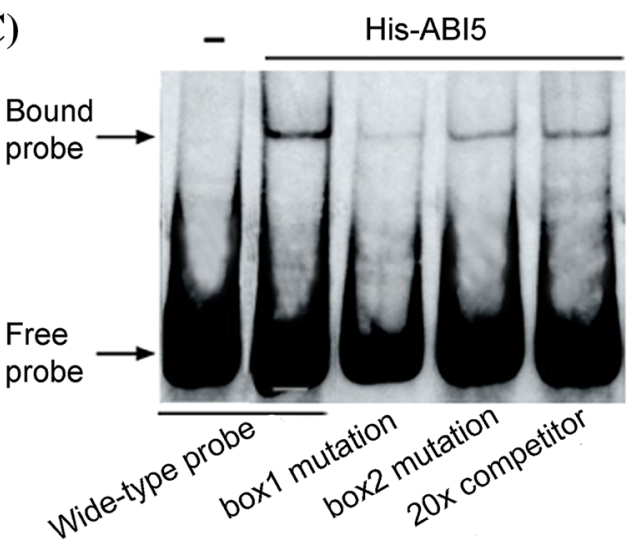

(E)

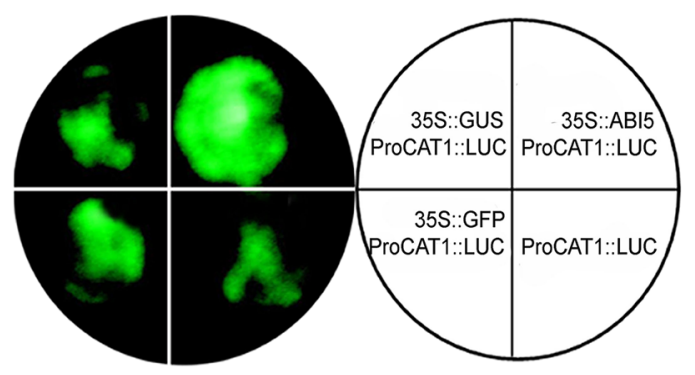

(D)

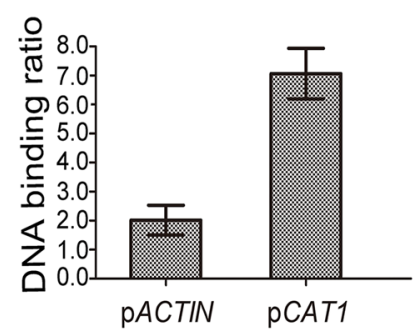

(F)

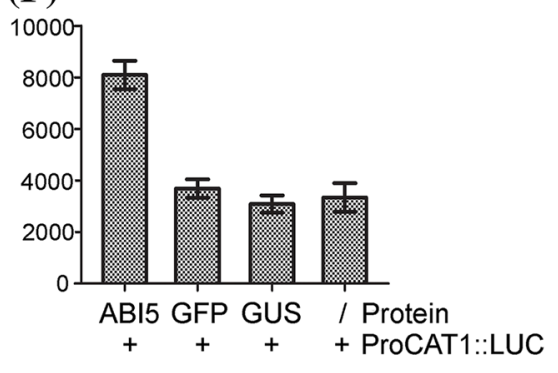

the seeds of wild-type and abi5-1. We performed RNAsequencing (RNA-seq) analyses on wild-type and abi5-1. The differently expressed genes in Col-0 and abi5-1 were analyzed. A total of 16,561 genes were found in Col-0 seeds, and of 16,116 genes in abi5-1 seeds (Supplemental Fig. S2A). Using the twofold change and the false discovery rate (FDR), 0.05 as the p-value cutoff for selecting the differentially expressed transcripts, lots of differentially expressed genes (DEGs) were found (Fig. 8a; Supplemental Fig. S2b). Among of these DEGs, there were 616 genes which were induced and 1303 genes which were repressed in abi5-1 seeds (Supplemental Tables S9, S10).

In this study, we focused on the genes that are responsible for ROS metabolism or in response to ROS. The Gene 
4Fig. 6 ABI5 can directly bind to the promoter of CAT1 in vitro and activate $C A T 1$ expression in vivo. a Yeast one-hybrid assay. The prey vector harboring ABI5 (indicated by pGADT7-ABI5) and the bait vector pHIS2 harboring CAT1 promoter (indicated by pHIS2-CAT1) were used to co-transform yeast cells. The transformation with vectors pHIS2-53 and pHIS2-CAT2 was taken as a negative control. The experiments were repeated three times with the same results. b The promoter structure of CAT1 gene. The box 1 and box 2 denote two G-box from left to right with sequence sites relative to the star code. The fragment from -296 to -108 indicates the sequence used in electrophoretic mobility shift assay described in the panels. c Electrophoretic mobility shift assay shows that ABI5 can bind the boxl site and box 2 site. The 6 His tag peptide (6His), which was fused to ABI5 protein for ABI5 protein production. "-" represents that 6 His was served as a negative control. Box 1 mutation is ACGT $\rightarrow$ TTTT, and box 2 mutation is ACGT $\rightarrow$ TTTT (see Methods section). Wild type probe, not mutation labeled probe; box 1 mutation, box 1 mutation labeled probe; box 2 mutation, box 2 mutation labeled probe; $20 \times, 20$-fold unlabeled probes as competitors. Black arrow means shift band. These experiments were repeated six times substantially with the same results. d ChIP-qPCR assays were performed using the specific primer corresponding to the $C A T 1$ promoter region. The ACTIN promoter was used as a negative control. Primers used in the ChIP-qPCR assays are indicated by arrows and are presented in Fig. 6b. Each data bar represents mean $\pm \mathrm{SE}(\mathrm{n}>3)$. Similar results were obtained from four independent experiments. e Test of the interactions of ABI5 with the $C A T 1$ promoter in vivo in tobacco leaves. The tobacco leaves were transformed with the following constructs all together with ProCAT1::LUC. The control constructs harbor GFP and GUS encoding open reading frame, called "35S::GFP" and "35S::GUS" respectively. Co-expressed the constructs of "35S::ABI5" with ProCAT1::LUC can active the activity of ProCAT1::LUC, but controls cannot. f Quantitative analyses of luminescence intensity are shown in e. The panels show the corresponding quantitative data corresponding to fluorescent images. Each value is the mean $\pm \mathrm{SE}$ with five independent determinations. The experiments were performed three biological repeats and obtained the similar trend

Ontology (GO) analysis indicated that among these downregulation DEGs, there were many genes which participate in oxygen and ROS metabolic process and regulation of $\mathrm{H}_{2} \mathrm{O}_{2}$ metabolic process (Fig. 8b). About $10 \%$ of the DEGs involved in oxygen and ROS metabolic process showed obviously down-regulation, including AT WRKY40 (AT1G80840), an peroxisomal NAD-malate dehydrogenase (AT5G09660), and so on (Table 1). Furthermore, among 34 DEGs related to oxygen and reactive oxygen species metabolic process, there were 25 genes involved in $\mathrm{H}_{2} \mathrm{O}_{2}$ metabolic process. Some genes in response to oxidative stress were up-regulated in abi5-1, which might be the feedback due to abi5 mutation impairing ROS signaling by inactivating ROS regulators (Table 1). Besides, due to the disruption of $A B I 5$, expressions of some genes, participating in GA metabolism, GA signaling, ABA metabolism and ABA signaling, changed significantly, showing that they were involved in the process of ABI5 regulating seed germination (Table 2).

Surprisingly, we did not find CATl transcript in the DEGs. It seemed to contradict with the result of RTPCR (Fig. 4a). It has been well known that, because of the technical biases in RNA-seq library generation and sequencing, false positive and false negative results will be produced in RNA-Seq data (Langmead et al. 2009; Zheng and Moriyama 2013). On the other hand, absence of CAT1 transcript in DEGs could be connected with possible differences in sampling between the RT-PCR and RNA-SEq. To ensure the reliability of our RNA-Seq data, we analyzed the expressions of ABI5 target genes in RNA-Seq data, including EM1 and EM6 (Carles et al. 2002). Both EM1 and EM6 showed down-regulation in abi5-1, which suggested that our RNA-Seq results were reliable (Supplemental Tables S11).

Also, in the RT-PCR analyses of the expression of EMI and EM6 in abi5-1, we showed that their expression were down-regulated due to the disruption of $A B I 5$ (Fig. 9).

\section{3-AT treatment alters expressions of genes correlative to seed germination in Col-0, ABI5OE-Myc and abi5-1 seeds}

By analyzing RNA-Seq data, we found that many vital genes involved in seed germination expressed differentially between Col-0 and abi5-1 mutant (Table 2). To exploring the effects of 3-AT on gene expressions, we analyzed the transcript levels of EM1, EM6, DOG1, GA3ox, NCED9 and PYL7 using quantitative RT-PCR analysis in the seeds of Col-0, ABI5OE-Myc and abi5-1 which were treated with or without $5 \mathrm{mM} 3$-AT. The results of RT-PCR showed the same change trend of these genes as that shown in RNASeq data without 3-AT treatment in Col-0 and abi5-1 (Fig. 9). This was also the important evidence of reliability about the RNA-Seq data.

EM1 and EM6 are ABA-responsive genes, which function in seed development (Gaubier et al. 1993; Carles et al. 2002). DOG1 (DELAY OF GERMINATION 1) was identified as a major regulator of dormancy in various species (Bentsink et al. 2006; Graeber et al. 2010). Here, we found that the change in $A B I 5$ expression had effects on these gene expressions, especially in abi5-1 seeds. When treated by $5 \mathrm{mM} 3$-AT, EM1 and EM6, which functions in promoting seed germination, were dominantly down-regulated in Col-0, which could partly explain the inhibition of 3-AT on seed germination of Col-0. Contrarily, DOG1, which functions in delaying seed germination, was up-regulated in Col-0 and abi5-1, while down-regulated in ABI5OE-Myc under 3-AT treatment (Fig. 9). The different effects of 3-AT on gene expressions in Col-0, ABI5OE-Myc and abi5-1 could be responsible for their different phenotypes during seed germination.

In addition, we found that 3-AT can affect the expression of genes involved ABA and GA metabolism differently in Col-0, ABI5OE-Myc and abi5-1. Genetic and physiological evidence supports the importance of two hormones, 


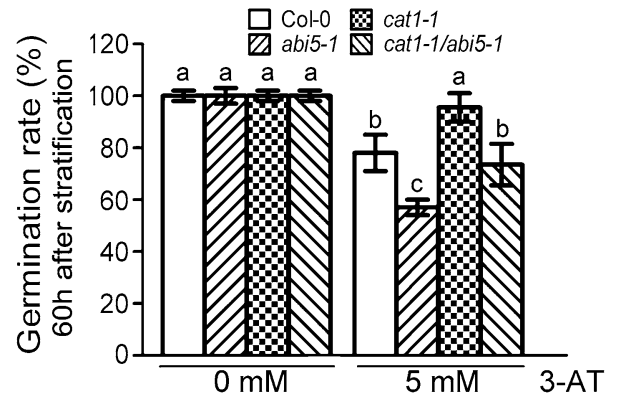

Fig. 7 Genetic evidence supports that CAT1 plays a role directly of ABI5 downstream. The cat1 mutation can suppress 3-AT hypersensitive phenotype of abi5-1 in seed germination. Seed germination rate of the wild-type plants (Col-0) and mutants, including cat1-1, abi5-1, and cat $1-1$ abi5-1 was recorded in 3-AT free medium and 3-AT containing medium $(5 \mathrm{mM})$ at $60 \mathrm{~h}$ after stratification. Each value is the mean \pm SE of five independent biological determinations, and different letters indicate significant differences at $\mathrm{P}<0.05$ (Duncan's multiple range test) when comparing values within the same 3-AT concentration

(A)

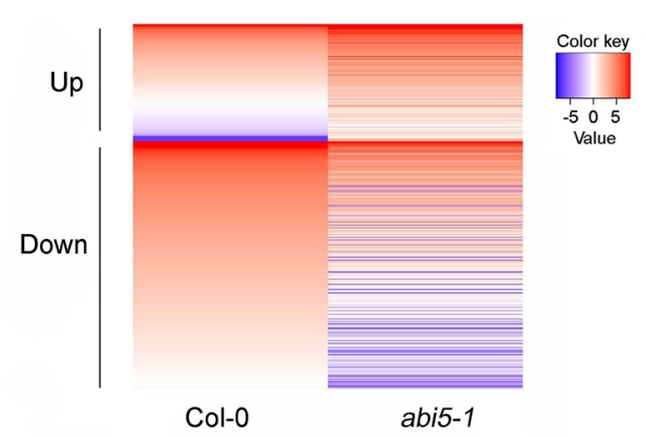

(B)

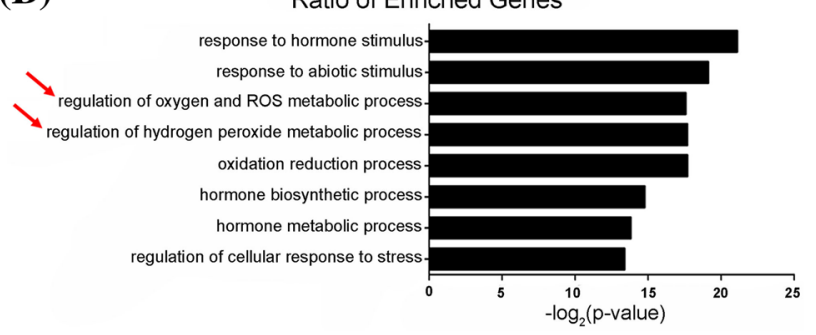

Fig. 8 RNA sequencing analysis of differentially expressed transcripts in the seeds of wild-type (Col-0) and knockout mutant abi51. a Diagrams show the number of the differentially expressed genes up- or down-regulated in Col-0 and abi5-1 mutant. The heatmap shows the differentially expression of 616 up-regulated genes and 1303 down-regulated genes with a cut-off value $=$ twofold or 0.5 -fold (FDR $\leq 0.05)$. All comparisons were made relative to the gene expression level of the wild type (Col-0). b GO analysis of 1303 down-regulated genes. Diagrams show the functional distribution of the ratio of enrichment genes among 1303 down-regulated genes. Red arrows show ROS-related genes abscisic acid (ABA) and gibberellins (GAs), in seed dormancy and germination (Koornneef et al. 2009; Finkelstein et al. 2000). NCED9 regulates a key step of ABA biosynthesis (Lefebvre et al. 2006), while GA3ox is an vital enzyme in GA biosynthesis (Yamaguchi 2008). Without 3-AT treatment, NCED9 and GA3ox showed up-regulated and down-regulated in abi5-1, respectively. Combined with the expression of EM1,EM6 and DOG1, their expression changes tended to inhibit seed germination of abi5- 1 in the presence of 3-AT treatment. However, there was no difference on the seed germination of Col-0, ABI5OE-Myc and abi5-1 without 3-AT treatment. It seemed that there was delicate and complicated balance among genes correlative to seed germination. Due to 3-AT treatment, the balance was disrupted, which resulted in different 3-AT phenotypes of Col-0, ABI5OE-Myc and abi5-1.

PYL7 is a member of ABA receptors (Park et al. 2009). The change in $A B I 5$ expression resulted in increasing of PYL7 expression in Col-0, ABI5OE-Myc and abi5-1 under 3-AT treatment (Fig. 9). This suggested that 3-AT can affect seed germination mediated by ABI5 partly depending on ABA signaling.

\section{Discussion}

It is well known that ABI5 is a positive regulator in ABA signaling (Finkelstein 1994a, b). Lots of evidence shows that ABI5 regulates seed germination by regulating ABA signaling or the expression of genes involved in seed development. For instance, it binds to EMs promoter and affects their expression (Carles et al. 2002). Here we found that 3-AT, a kind of catalase activity inhibitor, could affect seed germination mediated by ABI5. In the absence of 3-AT, seed germination of abi5 mutants and ABI5OE lines showed the same germination rates as that of Col-0. In the presence of 3-AT, seed germination of abi5-1 and abi5-7 showed strong 3-AT-hypersensitive phenotypes compared with wild-type seeds. Meanwhile, the seeds of ABI5OE lines, including ABI5OE-Myc and ABI5OE-GFP, showed a significantly 3-AT-insensitive phenotype (Fig. 1). Whether is ROS involved in seed germination mediated by ABI5? We observed the phenotypes of Col-0, abi5 mutants and ABI5OE lines on the MS medium with different concentrations of $\mathrm{H}_{2} \mathrm{O}_{2}$ during seed germination. The results showed that abi5 mutants were hypersensitive to $\mathrm{H}_{2} \mathrm{O}_{2}$, while $\mathrm{ABI} 5 \mathrm{OE}$ lines were insensitive, compared with Col-0 (Fig. 2), which was the direct evidence on that ROS was involved in seed germination mediated by ABI5. 3-AT, which is a CAT activity inhibitor, can affect ROS homeostasis by promoting $\mathrm{H}_{2} \mathrm{O}_{2}$ accumulation in the cell. The seed germination phenotypes of abi5 mutants and ABI5OE lines in the medium containing different concentrations of 
Table 1 Go analysis of differentially expressed genes in Col-0 and abi5-1

\begin{tabular}{|c|c|c|c|c|c|c|c|c|}
\hline $\begin{array}{l}\text { Gene set } \\
\text { name(no. } \\
\text { genes) }\end{array}$ & Description & $\begin{array}{l}\text { Gene number } \\
\text { in overlap }\end{array}$ & $\begin{array}{l}\text { Fold change } \\
(\text { abi5-1/Col-0) }\end{array}$ & Gene names & & & & \\
\hline \multirow{7}{*}{$\begin{array}{l}\text { OXYGEN_- } \\
\text { AND_REAC- } \\
\text { TIVE_OXY- } \\
\text { GEN_SPE- } \\
\text { CIES_MET- } \\
\text { ABOLIC_- } \\
\text { PRO- } \\
\text { CESS(347) }\end{array}$} & \multirow{7}{*}{$\begin{array}{l}\text { GO:0006800 oxygen } \\
\text { and reactive } \\
\text { oxygen species } \\
\text { metabolic process, } \\
\text { GOslim:biological_ } \\
\text { process }\end{array}$} & \multirow[t]{7}{*}{34} & \multirow{7}{*}{$\begin{array}{l}\text { Down-regula- } \\
\text { tion }\end{array}$} & AT5G02790 & AT3G55800 & AT1G80840 & AT4G13510 & AT1G19670 \\
\hline & & & & AT4G16190 & AT5G09660 & AT1G33590 & AT4G33560 & AT2G20570 \\
\hline & & & & AT5G24530 & AT3G09940 & AT2G36470 & AT2G26400 & AT1G32060 \\
\hline & & & & AT1G59870 & AT1G77120 & AT1G74710 & AT4G33070 & AT1G02220 \\
\hline & & & & AT1G20020 & AT5G20480 & AT2G28200 & AT5G66570 & AT5G21090 \\
\hline & & & & AT3G28930 & AT3G14150 & AT5G60360 & AT2G44490 & AT1G68520 \\
\hline & & & & AT1G54410 & AT1G66880 & AT1G18570 & AT1G66200 & \\
\hline \multirow{5}{*}{$\begin{array}{l}\text { REGULA- } \\
\text { TION_OF_ } \\
\text { HYDRO- } \\
\text { GEN_PER- } \\
\text { OXIDE_- } \\
\text { META- } \\
\text { BOLIC_PRO- } \\
\text { CESS(187) }\end{array}$} & \multirow{5}{*}{$\begin{array}{l}\text { GO:0010310 } \\
\text { regulation of } \\
\text { hydrogen peroxide } \\
\text { metabolic process, } \\
\text { GOslim:biological_ } \\
\text { process }\end{array}$} & \multirow[t]{5}{*}{25} & \multirow{5}{*}{$\begin{array}{l}\text { Down-regula- } \\
\text { tion }\end{array}$} & AT1G80840 & AT1G59870 & AT3G28930 & AT1G32060 & AT2G44490 \\
\hline & & & & AT5G24530 & AT1G20020 & AT4G33560 & AT5G20480 & AT1G18570 \\
\hline & & & & AT5G09660 & AT5G66570 & AT2G20570 & AT4G33070 & AT1G66880 \\
\hline & & & & AT1G33590 & AT1G74710 & AT1G19670 & AT2G36470 & AT1G54410 \\
\hline & & & & AT4G13510 & AT1G77120 & AT3G55800 & AT2G26400 & AT1G68520 \\
\hline \multirow{5}{*}{$\begin{array}{l}\text { RESPONSE_ } \\
\text { TO_OXI- } \\
\text { DATIVE_- } \\
\text { STRESS } \\
(582)\end{array}$} & \multirow{5}{*}{$\begin{array}{l}\text { GO:0006979 } \\
\text { response to } \\
\text { oxidative stress, } \\
\text { GOslim:biological_ } \\
\text { process }\end{array}$} & \multirow[t]{5}{*}{22} & \multirow[t]{5}{*}{ Up-regulation } & AT1G60970 & AT2G31570 & AT5G64510 & AT5G16960 & AT2G39800 \\
\hline & & & & AT2G40880 & AT1G71000 & AT2G22080 & AT5G39610 & AT1G14200 \\
\hline & & & & AT4G33940 & AT4G08770 & AT1G13340 & AT1G69270 & AT3G60980 \\
\hline & & & & AT1G35720 & AT5G40390 & AT5G16990 & AT4G34890 & AT1G50290 \\
\hline & & & & AT2G47180 & AT1G09080 & & & \\
\hline
\end{tabular}

P-value < 0.05; Differentially expressed genes twofold-down-expression change or twofold-up-expression change

Table 2 Differentially expressed genes related to seed germination and ROS metabolism in Col-0 and abi5-1

\begin{tabular}{|c|c|c|c|c|c|}
\hline Gene_ID & Gene names & $\begin{array}{l}\text { Fold change } \\
\text { (abi5-1/Col-0) }\end{array}$ & Up/Down & Gene description & Pathway \\
\hline AT1G15550 & GA3OX1 & 0.158792 & Down & Gibberellin 3-oxidase 1 & GA biosynthesis \\
\hline AT1G66350 & RGL1 & 0.394985 & Down & RGA-like 1 & GA signaling \\
\hline AT5G45830 & DOG1 & 8.766422 & Up & Delay of germination 1 & Seed development \\
\hline AT3G51810 & EM1 & 0.169394 & Down & Stress induced protein & \\
\hline AT2G40170 & EM6 & 0.477625 & Down & Stress induced protein & \\
\hline AT1G78390 & NCED9 & 2.70285 & Up & Nine-cis-epoxycarotenoid dioxygenase 9 & ABA metabolism \\
\hline AT2G40330 & PYL6 & 0.450936 & Down & PYR1-like 6 & ABA signaling \\
\hline AT2G26040 & PYL2 & 0.493138 & Down & PYR1-like 2 & \\
\hline AT2G38310 & PYL4 & 0.410952 & Down & PYR1-like 4 & \\
\hline AT4G01026 & PYL7 & 5.927423 & Up & PYR1-like 7 & \\
\hline AT3G19290 & ABF4 & 3.243769 & Up & ABRE binding factor 4 & \\
\hline AT5G57050 & $\mathrm{ABI} 2$ & 2.09312 & Up & Protein phosphatase $2 \mathrm{C}$ family protein & \\
\hline AT2G31570 & GPX2 & 3.094566 & Up & Glutathione peroxidase 2 & ROS metabolism \\
\hline AT4G11600 & GPX6 & 0.483308 & Down & Glutathione peroxidase 6 & \\
\hline AT1G77490 & APXT & 2.813915 & Up & Thylakoidal ascorbate peroxidase & \\
\hline AT2G35690 & ACX1.2 & 4.115625 & Up & Acyl-CoA oxidase 5 & \\
\hline
\end{tabular}

P-value $<0.05$; Differentially expressed genes twofold-down-expression change or twofold-up-expression change

exogenous $\mathrm{H}_{2} \mathrm{O}_{2}$ was similar to that in different concentrations of 3-AT medium, which further confirmed that ABI5 regulated seed germination partly depending on the ROS signaling pathways.
CAT members are the vital enzymes scavenging $\mathrm{H}_{2} \mathrm{O}_{2}$, but their functions in seed germination have not been clearly identified in Arabidopsis. Previous results suggested that the CATI gene is mainly expressed in pollen 


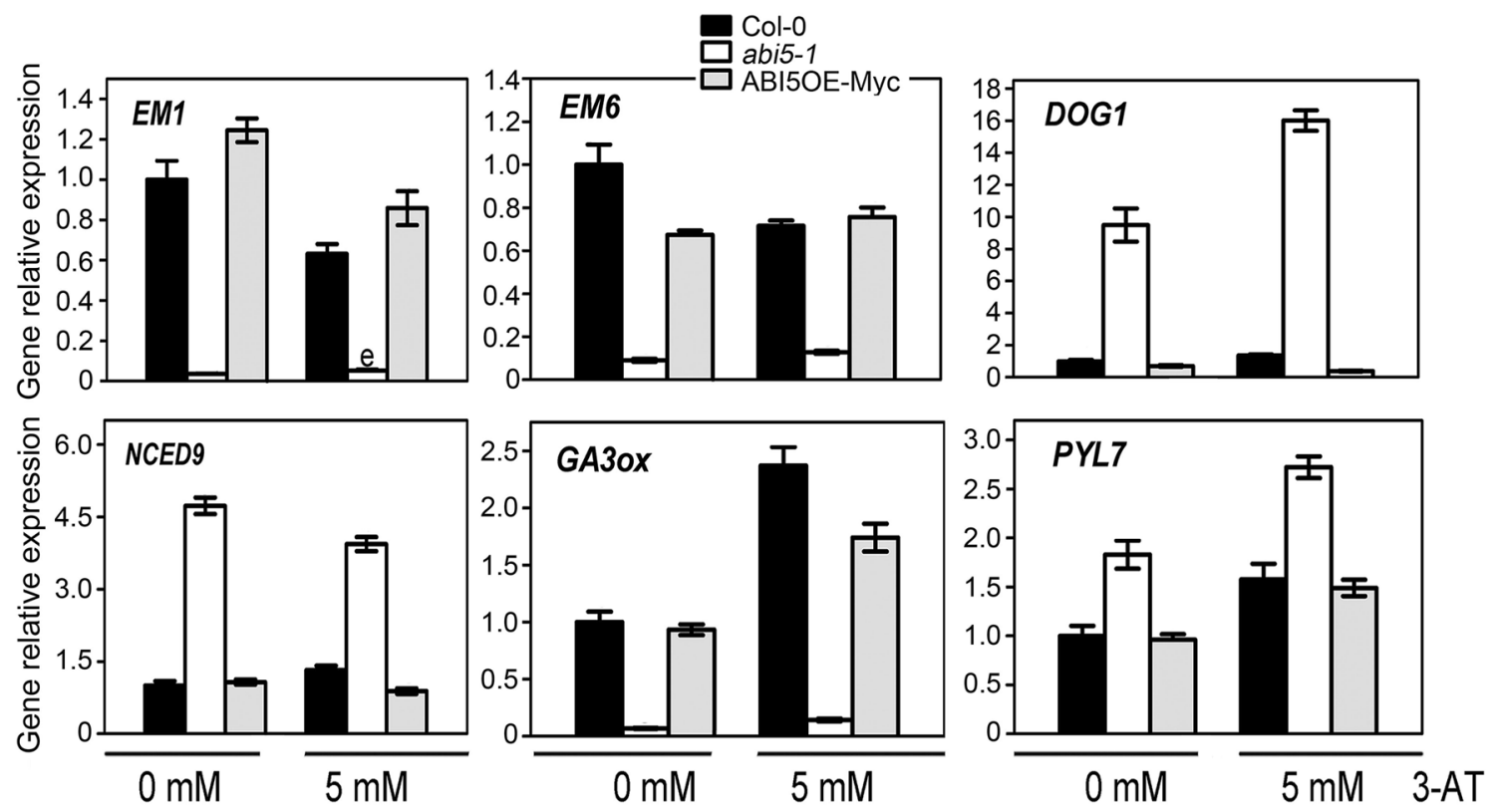

Fig. 9 3-AT alters the expressions of genes related to seed germination due to $A B I 5$ disruption and overexpression. Seeds of Col-0, ABI5OE-Myc and abi5-1, were treated with or without $5 \mathrm{mM} 3-\mathrm{AT}$ and grown under 16-h light/8-h dark conditions for $24 \mathrm{~h}$ after strati-

and seeds, CAT2 in photosynthetic tissues but also in roots and seeds, while CAT3 is associated with vascular tissues but also leaves (Du et al. 2008). This means that they will function in different tissues and development process. The further evidence showed that different CAT members may play different roles during the same process. Previous studies indicated that ABA has an opposite effect on the transcription of CAT1 and CAT2 in barley aleurone, which suggests that they play the opposing roles (Fath et al. 2001). In our study, CAT mutants differed in their 3-AT phenotypes with regard to seed germination. Phenotypes of $C A T 1$ and CAT2 mutants were completely opposite to those of CAT3 mutants (Fig. 3d). By examining the RNA and protein expression of three CAT members, we found that there was a difference at RNA and protein level in different $C A T$ mutants without 3-AT treatment. At the RNA level, the expression changes in any members can induce the expression changes in other members more or less (Fig. 3b). But at the protein level, in addition to the CAT1 mutation, both CAT2 and CAT3 mutations could affect the expression of CAT family obviously (Fig. 3c). There may be an unknown mechanism on the difference of CAT expression at RNA and protein level. Moreover, there is a delicate balance among the CAT members during seed germination in response to 3-AT treatment. The final status of the balance between the three CAT genes determines the germination phenotype under 3-AT treatment. fication. The transcript levels of EM1, EM6, DOG1, NCED9, GA3ox and PYL7 were examined using quantitative RT-PCR analysis. Each value is the mean $\pm \mathrm{SE}$ of three independent experiments

We examined the CAT protein and catalase activity in seeds of Col-0, abi5-1 and ABI5OE-Myc with or without 3-AT treatment. The abi5 mutation or ABI5 overexpression could result in the changes in CAT protein and catalase activity (Figs. 4, 5). Furthermore, 3-AT treatment could significantly affect the catalase activity differently in Col0, abi5-1 and ABI5OE-Myc seeds (Fig. 5c, d), but 3-AT treatment did not obviously change the CAT protein levels (Fig. 4d). We thought that the difference of CAT protein levels in Col-0, abi5-1 and ABI5OE-Myc was a vital reason resulting in the difference of catalase activity in response to 3-AT treatment. For example, because of CAT protein accumulation in abi5-1, 3-AT had a more obvious inhibition on catalase activity in abi5-1. The balance of CAT protein levels and catalase activity decided the final $\mathrm{H}_{2} \mathrm{O}_{2}$ content, which should be connected with the seed germination phenotypes in Col-0, abi5 mutants and ABI5OE lines under the 3-AT treatment. But under normal condition, the fundamental difference of $\mathrm{H}_{2} \mathrm{O}_{2}$ content was not enough to affect the ROS homeostasis, so there was no difference in seed germination of Col-0, abi5 mutants and ABI5OE lines. But 3-AT treatment could disrupt ROS homeostasis, which resulted in the difference of seed germination rate in Col-0, abi5 mutants and ABI5OE lines. So we suggested that the direct reason for different germination rate is the change in $\mathrm{H}_{2} \mathrm{O}_{2}$ content due to breaking the balance of CAT protein and catalase activity under the 3-AT treatment. 
Based on above results, it was shown that ROS played a vital role in the seed germination mediated by ABI5.

Furtherly, RNA-Seq data supported that disruption of ABI5 could alter expressions of genes participating in ROS metabolism, especially $\mathrm{H}_{2} \mathrm{O}_{2}$ metabolism, and ROS signaling (Table 1). Combining with RNA-Seq data, we used RT-PCR to examine the effects of 3-AT treatment on the DEGs involved in seed germination in Col-0, abi5-1 and ABI5OE-Myc. The results showed that due to different expression of $A B I 5,3$-AT had different effects on expressions of these vital genes, which were involved in seed development, ROS metabolism, GA metabolism, GA signaling, ABA metabolism, ABA signaling and so on (Fig. 9; Table 2).

In addition, biochemical and physiological evidence supported that ABI5 could affect the balance of three CAT members by regulating the $C A T 1$ expression directly (Fig. 6). Previous evidence has shown that plants have evolved the complex defense systems to regulate the homeostasis of the intracellular $\mathrm{H}_{2} \mathrm{O}_{2}$ level, which plays a vital role during the plant evolution process (Mhamdi et al. 2010). $\mathrm{H}_{2} \mathrm{O}_{2}$ is a major ROS, and the balance of the CAT protein and catalase activity, which conjointly determines the $\mathrm{H}_{2} \mathrm{O}_{2}$ content, should be the key factor in charge of ROS homeostasis. Previous research on ABI5 regulating seed germination is focused on ABA signaling. Here we proposed that ABI5 affects seed germination partly dependent on ROS. Much evidence has shown the crosstalk of ROS signaling, abscisic acid and ethylene signaling (Bueso et al. 2007; El-Maarouf-Bouteau et al. 2015). Our data illustrated a new crosstalk among different signaling during the seed germination mediated by ABI5. Taken together, a new mechanism of ABI5 regulating the process of seed germination was demonstrated, in which CAT acted as a link between the ABI5 and ROS homeostasis. Moreover, the different roles of CAT members in mediating ROS signaling in seeds were demonstrated.

\section{Materials and methods}

\section{Plant materials and growth conditions}

The mutant Arabidopsis lines cat1-1 (SAIL_525_C10), cat1-3 (SALK_208924), cat2-2 (SALK_057998), cat23 (SALK_144919), cat3-1 (SALK_092911) and cat3-2 (SALK_088601) were obtained from the Arabidopsis Biological Resource Center (Columbus, OH, USA). The homozygous mutants were identified by PCR using genespecific primers (Supplemental Table S1). The mutated $A B I 5$ gene in the abi5-1 mutant (ABRC Stock Number CS8105; named abi5-1 in this report) was transferred from its background Wassilewskija (Ws) ecotype into Col-0 ecotype by backcrossing (Liu et al. 2012). For the generation of the transgenic lines of ABI5OE-GFP, the open reading frame (ORF) sequences of $A B I 5$ was amplified by PCR and cloned into the binary vector pCAMBIA-1300-221 (http://www.cambia.org) with a green fluorescent protein (GFP) tag which contains the cauliflower mosaic virus $35 \mathrm{~S}$ promoter. The specific primers used for generating the ABI5OE-GFP are listed in Supplemental Table S7. Some of plant materials used in this study were previously described: abi5-7 and ABI5OE-Myc (Bu et al. 2009). We examined ABI5 expression in abi5-1, abi5-7, ABI5OEMyc and ABI5OE-GFP by RT-PCR (Supplemental Fig. S3).

Arabidopsis seeds were disinfected and plated on MS medium (Phyto Technology Laboratories, USA, product No. M519) supplemented with 3\% sucrose and 0.8\% agar (pH 5.9), chilled for 3 days at $4{ }^{\circ} \mathrm{C}$ and transferred to a growth chamber at $80 \mu \mathrm{mol}$ photons $\mathrm{m}^{-2} \mathrm{~s}^{-1}$ or to compost soil at $120 \mu \mathrm{mol}$ photons $\mathrm{m}^{-2} \mathrm{~s}^{-1}$ using cool white fluorescent lamps under a $16 \mathrm{~h}$-light/8 $\mathrm{h}$-dark photoperiod and $60 \%$ relative humidity.

\section{Phenotypic analysis}

Phenotypic analysis was performed as described previously (Wu et al. 2009; Shang et al. 2010). For germination assays, $\sim 100$ seeds were sterilized and plated in triplicate on MS medium (Phyto Technology Laboratories, USA, product No. M519). The medium contained 3\% sucrose and $0.8 \%$ agar ( $\mathrm{pH}$ 5.9) supplemented with or without different concentrations of 3-AT (3-amino-1,2,4-triazole; Sigma, USA, product No. A8056) or $\mathrm{H}_{2} \mathrm{O}_{2}$. The seeds were chilled at $4{ }^{\circ} \mathrm{C}$ for 3 days before being placed at $22^{\circ} \mathrm{C}$ under light conditions (16-h light/8-h dark), and germination (emergence of radicals) was scored at the indicated times.

\section{Quantitative RT-PCR analysis of mRNA expression}

For quantitative RT-PCR (qRT-PCR) analysis, total RNA was isolated from imbibing seeds, which were chilled for 3 days at $4{ }^{\circ} \mathrm{C}$ to stimulate germination and then placed at $22^{\circ} \mathrm{C}$ under a $16-\mathrm{h}$ light/8-h dark photoperiod for $24 \mathrm{~h}$. Total RNA was isolated using a seed RNA Extraction Kit (BioTeke, China, product No. RP1201), treated with RNase-free DNase I (NEB, USA, M0303) at $37{ }^{\circ} \mathrm{C}$ for 30 min to degrade genomic DNA, and purified by using an RNA Purification Kit (BioTeke, China, Product No. RP1801).

RNA $(2 \mu \mathrm{g})$ was subjected to first-strand cDNA synthesis using a kit according to the manufacturer's instructions (Roche Applied Science, USA, product No. AS095014379012001). The primers used for qPCR are listed in Table S1 in the Supporting Information. Analysis 
was performed using the Bio-Rad Real-Time System CFX96TM C1000 Thermal Cycler (Bio-Rad, USA). All experiments were repeated at least three times.

The qRT-PCR analysis was performed using the SYBR Green kit (Takara, Japan). PCR conditions were as follows: 10 min of denaturation at $95^{\circ} \mathrm{C}$, followed by 45 cycles of $10 \mathrm{~s}$ of denaturation at $95^{\circ} \mathrm{C}, 5 \mathrm{~s}$ of annealing at $55^{\circ} \mathrm{C}$ and a $10 \mathrm{~s}$ extension at $72^{\circ} \mathrm{C}$. The mRNA levels were measured relative to the constitutive ACTIN 2/8 mRNA (Wallström et al. 2012). All the gene-specific primers for real-time PCR analysis were shown in Supplemental Table S8.

\section{Protein gel blot analysis}

Protein extraction of Arabidopsis seeds was performed essentially according to previously described procedures (Wu et al. 2009; Shang et al. 2010). The seeds were frozen in liquid nitrogen, ground in a pre-chilled mortar with a pestle to a fine powder and transferred to a $1.5 \mathrm{~mL}$ tube. The extraction buffer consisted of $50 \mathrm{mM}$ Tris- $\mathrm{HCl}$ (pH 7.5), $150 \mathrm{mM} \mathrm{NaCl}, 1 \mathrm{mM}$ EDTA, $0.1 \%$ (v/v) Triton $\mathrm{X}-100,10 \%(\mathrm{v} / \mathrm{v})$ glycerol and a protein inhibitor cocktail (Roche). The extraction buffer was added to the tube (20 mL buffer/g sample) and was placed on ice for $2 \mathrm{~h}$. The mixture was centrifuged for $10 \mathrm{~min}$ at $12,000 \mathrm{rpm}$ at $4{ }^{\circ} \mathrm{C}$ to remove insoluble material, and the supernatant was transferred to a defatted column (PEXBIO, China, product No. A020208C). After centrifugation for $2 \mathrm{~min}$ at 12,000 rpm at $4{ }^{\circ} \mathrm{C}$, the sample in the collection column was ready for use.

SDS-PAGE and protein gel blot analysis were performed essentially according to previously described procedures (Wu et al. 2009; Shang et al. 2010). Specific antibody against CAT was purchased from Agrisera (Stockholm, Sweden; website: http://www.agrisera.com; product No. AS09501).

\section{Catalase Activity Assays}

Protein was extracted from imbibing seeds, which were chilled for 3 days at $4{ }^{\circ} \mathrm{C}$ to stimulate germination and then placed at $22^{\circ} \mathrm{C}$ under a 16 -h light/8-h dark photoperiod for $24 \mathrm{~h}$ with different treatment. The supernatant was used as the crude extract and catalase activity was tested with the Catalase Activity Assay Kit (Beyotime, China, product No. S0051). Protein concentration was determined using the Bradford protein assay. Crude extract $(5 \mu \mathrm{L})$ was mixed with catalase testing buffer, and $250 \mathrm{mM} \mathrm{H}_{2} \mathrm{O}_{2}$ was used as the substrate. Reaction time was strictly controlled and stopped with addition of stop buffer. The mixture was then added into the working color solution and incubated for at least $15 \mathrm{~min}$. Absorbance at $520 \mathrm{~nm}$ was measured and activity was calculated. Catalase activity was indicated in units $/ \mathrm{mL}$ or units $/ \mathrm{mg}$. One unit of catalase activity is defined as the quantity of enzyme catalyzing the decomposition of $1 \mathrm{mM} \mathrm{H}_{2} \mathrm{O}_{2}$ per minute.

\section{Determination of $\mathrm{H}_{2} \mathrm{O}_{2}$ content}

$\mathrm{H}_{2} \mathrm{O}_{2}$ in seeds was quantified using the Hydrogen Peroxide Assay Kit according to the manufacturer's instructions (Beyotime, China, product No. S0038). The imbibition seeds which were chilled for 3 days at $4^{\circ} \mathrm{C}$ to stimulate germination and then placed at $22^{\circ} \mathrm{C}$ under a 16 -h light/8$\mathrm{h}$ dark photoperiod for $24 \mathrm{~h}$ were ground into powders. Then the seed powder was added to the tube by $20 \mathrm{~mL}$ lysis buffer of Hydrogen Peroxide/g sample. The samples were centrifuged at $4{ }^{\circ} \mathrm{C}, 12,000 \times g$ for $5 \mathrm{~min}$ to gather the supernatants for the following tests. A $50 \mu \mathrm{L}$ volume of each supernatant was then transferred to a 96-well microtiter plate. A $100 \mu \mathrm{L}$ volume detection solutions of Hydrogen Peroxide was added to each well and thoroughly mixed with the supernatant. After incubation at room temperature for $30 \mathrm{~min}$, the plates were read using a spectrophotometer (Synergy ${ }^{\mathrm{TM}} \mathrm{H} 1$, Biotek, USA) at a wavelength of $560 \mathrm{~nm}$. The concentration of $\mathrm{H}_{2} \mathrm{O}_{2}$ was calculated according to standard concentration curve originated from standard solutions upon the identical experiments. All the operations were carried out on ice.

\section{Yeast one-hybrid assay}

Yeast one-hybrid assay was performed essentially as previously described (Shang et al. 2010) with the kit provided by Clontech (Matchmaker ${ }^{\mathrm{TM}}$ One-Hybrid Library Construction \& Screening Kit CATALOG No. 630304) using the Y187 yeast strain according to the manufacturer's instructions. The related cDNAs or promoter DNAs were amplified by PCR using the primer pairs as supplemental Table 3. The promoter fragments of CAT1 and CAT2 were sub-cloned into the $S m a I / M l u I$ sites of pHIS2 vector. ABI5 cDNA was sub-cloned into the EcoRI / BamHI sites of pGADT7 vector. Yeast cells were co-transformed with pHIS2 bait vector that harbored promoter of target genes and pGADT7 prey vector that contained ORF of ABI5. As negative controls, the yeast cells were transformed with pGADT7-ABI5 vector with pHIS2-p53 (Wei et al. 2006) or pHIS2-CAT2 harboring the corresponding promoter. Transformed yeast cells were grown in the tryptophan (Trp) and leucine (Leu)-deficient SD medium (SD-Trp-Leu) to ensure that the yeast cells were successfully co-transformed, and then the yeast cells were grown on the plates of the tryptophan (Trp), leucine (Leu) and histidine (His)deficient SD medium (SD-Trp-Leu-His) supplemented with 3-AT (Sigma) at $0,10,20$, and $50 \mathrm{mM}$. The plates were then incubated at $30^{\circ} \mathrm{C}$ for 3 days for investigations. 


\section{Electrophoretic mobility shift assay (EMSA)}

EMSA was performed essentially as previously described (Shang et al. 2010) using the recombinant His-ABI5 protein purified from E. coli strain BL21 (DE3) as mentioned above. ABI5 cDNA was sub-cloned into the SalI/EcoRI sites of pMAL-c5X vector (NEB). The biotin-labeled probes used for this EMSAs were amplified by PCR. The promoter fragments used for the EMSA were amplified by PCR using the following primer pairs as supplemental Table 4. The site-specific mutations of the G-box, named box 1 mutation and box 2 mutation, were introduced into the CAT1 promoter sequences by the independent PCR.

Then the labeled probes $(20 \mathrm{fmol})$ were incubated with the recombinant His-ABI5 proteins $(1 \mu \mathrm{g})$ in a binding buffer solution ( $25 \mathrm{mM}$ HEPES, $40 \mathrm{mM} \mathrm{KCl}, 5 \mathrm{mM} \mathrm{MgCl}_{2}$, $1 \mathrm{mM}$ DTT, $1 \mathrm{mM}$ EDTA, and 8\% glycerol, $\mathrm{pH}$ 8.0) in the presence of $1 \mu \mathrm{g} / \mu \mathrm{L}$ of poly (deoxyinosinic-deoxycytidylic) sodium salt [poly(dI-dC)] (Sigma, USA, product No. $\mathrm{P} 4929$ ) for $30 \mathrm{~min}$ at room temperature. The DNA-protein reaction mixtures were separated on a $5 \%$ non-denaturing polyacrylamide gel (19:1 acrylamide:bisacrylamide) in $0.25 \mathrm{mM}$ Tris-borate-EDTA at $4{ }^{\circ} \mathrm{C}$, transferred onto a nylon membrane for $1 \mathrm{~h}$ at $4{ }^{\circ} \mathrm{C}$, exposed under ultra-violet light to cross-link the samples to the membrane for $2 \mathrm{~min}$. All the following procedures were performed by using the Light Shift Chemiluminescent EMSA kit (Thermo Scientific, product No. 89880) according to the manufacturer's instructions. The mutation probes were verified by sequence analysis. Competition experiments were performed using 20 -fold unlabelled fragments.

\section{Chromatin coimmunoprecipitation (ChIP) analysis}

The experiment was performed as described previously (Shang et al. 2010), using the seedlings of the 2-week-old ABI5OE-Myc transgenic plants and the wild-type (Col-0) plants for the ChIP assay. Immunoprecipitation was performed by using Rabbit anti-Myc-tag mAb-Magnetic beads (MBL, product No. M047-11). To determine quantitatively ABI5 binding to the CAT1 promoter, real-time PCR analysis was performed according to a procedure described previously with the Actin $23^{\prime}$-untranslated region sequence as the negative control (Shang et al. 2010). The primers used for real-time PCR analysis were listed in Supplementary Table S6. The experiment was repeated for three biological repeats with similar results.

\section{Cis-activation of CAT1promoter activity by ABI5 in tobacco leaves}

This assay was performed essentially according to the previously described procedures (Shang et al. 2010). ABI5 was used for the effector construct. The promoter of the CAT1 gene was amplified by PCR using the following primer pairs as supplemental Table S5. Then the reporter construct was composed of the CAT1 promoter linked to $L U C$. The cDNA of the ABI5 gene was fused to pCAMBIA1300-Myc vector downstream of the CaMV 35 S promoter and Myc tag. The cDNA of GUS and GFP were fused to pCAMBIA1300-Myc vector downstream of the CaMV $35 \mathrm{~S}$ promoter, which was used as an internal control. The constructs were mobilized into A. tumefaciens strain GV3101. Bacterial suspensions were infiltrated into young but fully expanded leaves of the 7-week old $N$. benthamiana plants using a needleless syringe. It is noteworthy that the amounts of the constructs were the same among treatments and controls for each group of assay. After infiltration, plants were grown firstly under dark for $24 \mathrm{~h}$ and then with $16 \mathrm{~h}$ light/day for $60 \mathrm{~h}$ at room temperature. The LUC activity was observed with a CCD imaging apparatus (Andor iXon, Andor, UK).

\section{RNA sequencing and bioinformatics analysis of RNA-Seq data}

For RNA sequencing (RNA-Seq) analysis, total RNA was isolated from imbibed seeds of wild type Col-0 and abi5-1 plants, which had been chilled for 3 days at $4{ }^{\circ} \mathrm{C}$ to stimulate germination and then placed at $22^{\circ} \mathrm{C}$ under a 16 - $\mathrm{h}$ light/8-h dark photoperiod for $24 \mathrm{~h}$. Total RNA was isolated using a seed RNA Extraction Kit (BioTeke, China, product No. RP1201), treated with RNase-free DNase I (NEB, USA, product No. M0303) at $37^{\circ} \mathrm{C}$ for $30 \mathrm{~min}$ to degrade genomic DNA, and purified by using an RNA Purification Kit (BioTeke, China, product No. RP1801). The construction of RNA libraries, RNA sequencing and bioinformatics analysis were performed at Bionova company (Beijing, China). For each sample, three biological replicates were sequenced. The raw sequence reads have been deposited into the GEO database under accession number GSE90004.

Acknowledgements Arabidopsis T-DNA insertion mutants were provided by ABRC. We thank Dr. Dong Liu for providing the constructs of "35S::GFP" and "35S::GUS" for luciferase complementation imaging assay, Dr. Shangchuan Jiang for providing the vector with cDNA of $A B I 5$ for LCI assay, Dr. Wei Chia-Lin providing the vector of $\mathrm{p} 53$ for yeast-one hybrid, and Dr. Chuanyou $\mathrm{Li}$ for providing seeds of abi5-7 and ABI5OE-Myc. We also thank Dr. Da-Peng Zhang for critical reading of the manuscript and stimulating discussions.

Author contributions X-FW initiated the research and prepared the article with input from all the authors. CB designed and conducted all the experiments. Other authors offered experimental instructions.

Funding This work was supported by the National Natural Science Foundation of China (Grant Nos. 31170268 and 31570275 to X.F.W.), the foundation for the Author of National Excellent Doctoral Dissertation of the PR China (FANEDD, Grant No. 201065 to 
X.F.W.), the National Key Basic Research Program of China (Grant No. 2012 CB114302 to D.P.Z.).

\section{Compliance with ethical standards}

Disclosures Xiao-Fang Wang initiated the research and prepared the article with input from all the authors. Chao Bi designed and conducted all the experiments. Other authors offered experimental instructions.

Open Access This article is distributed under the terms of the Creative Commons Attribution 4.0 International License (http:// creativecommons.org/licenses/by/4.0/), which permits unrestricted use, distribution, and reproduction in any medium, provided you give appropriate credit to the original author(s) and the source, provide a link to the Creative Commons license, and indicate if changes were made.

\section{References}

Albertos P, Romero-Puertas MC, Tatematsu K et al (2015) S-nitrosylation triggers $\mathrm{ABI} 5$ degradation to promote seed germination and seedling growth. Nat Commun 6:8669-8679

Apel K, Hirt H (2004) Reactive oxygen species: metabolism, oxidative stress, and signal transduction. Annu Rev Plant Biol 55:373-399

Bailly C (2004) Active oxygen species and antioxidants in seed biology. Seed Sci Res 14:93-107

Bailly C, El-Maarouf-Bouteau H, Corbineau F (2008) From intracellular signaling networks to cell death: the dual role of reactive oxygen species in seed physiology. C R Biol 331:806-814

Bentsink L, Jowett J, Hanhart CJ et al (2006) Cloning of DOG1, a quantitative trait locus controlling seed dormancy in Arabidopsis. Proc Natl Acad Sci 103(45): 17042-17047

$\mathrm{Bu} \mathrm{Q}, \mathrm{Li} \mathrm{H}$, Zhao Q et al (2009) The Arabidopsis RING finger E3 ligase RHA2a is a novel positive regulator of abscisic acid signaling during seed germination and early seedling development. Plant Physiol 150:463-481

Bueso E, Alejandro S, Carbonell P et al (2007) The lithium tolerance of the Arabidopsis cat 2 mutant reveals a cross-talk between oxidative stress and ethylene. Plant J 52:1052-1065

Carles C, Bies-Etheve N, Aspart L et al (2002) Regulation of Arabidopsis thaliana Em genes: role of ABI5. Plant J 30(3):373-383

Chen ZX, Silva H, Klessig DF (1993) Active oxygen species in the induction of plant systemic acquired-resistance by salicylic acid. Science 262:1883-1886

Chevalier C, Yamaguchi J, McCourt P (1992) Nucleotide sequence of a carrier DNA for catalase from Arabidopsis thaliana. Plant Physiol 99:1726-1728

Clark D, Durner J, Navarre DA et al (2000) Nitric oxide inhibition of tobacco catalase and ascorbate peroxidase. Mol Plant Microbe Interact 13:1380-1384

Dat J, Vandenabeele S, Vranová E et al (2000) Dual action of the active oxygen species during plant stress responses. Cell Mol Life Sci 57:779-795

Du YY, Wang PC, Chen J et al (2008) Comprehensive functional analysis of the catalase gene family in Arabidopsis thaliana. J Integr Plant Biol 50:1318-1326

Durner J, Klessig DF (1996) Salicylic acid is a modulator of tobacco and mammalian catalases. J Biol Chem 271:28492-28501

El-Maarouf-Bouteau H, Job C, Job D et al (2007) ROS signaling in seed dormancy alleviation. Plant Signal Behav 2:362-364
El-Maarouf-Bouteau H, Sajjad Y, Bazin J et al (2015) Reactive oxygen species, abscisic acid and ethylene interact to regulate sunflower seed germination. Plant Cell Environ 38:364-374

Fath A, Bethke PC, Jones RL (2001) Enzymes that scavenge reactive oxygen species are down-regulation prior to gibberellic acidinduced programmed cell death in barley aleurone. Plant Physiol 126:156-166

Finkelstein RR (1994a) Mutations at two new Arabidopsis ABA response loci are similar to the abi3 mutations. Plant J 5:765-771

Finkelstein RR (1994b) Maternal effects govern variable dominance of two abscisic acid response mutations in Arabidopsis thaliana. Plant Physiol 105:1203-1208

Finkelstein RR, Lynch TJ (2000) The Arabidopsis abscisic acid response gene ABI5 encodes a basic leucine zipper transcription factor. Plant Cell 12(4):599-609

Fontaine O, Huault C, Pavis N et al (1994) Dormancy break age of Hordeum vulgare seeds: effects of hydrogen peroxide and scarification on glutathione level and glutathione reductase activity. Plant Physiol Biochem 32:677-683

Foyer CH, Noctor G (2000) Oxygen processing in photosynthesis: regulation and signaling. New Phytol 146:359-388

Frugoli JA, Zhong HH, Nuccio ML et al (1996) Catalase is encoded by a multigene family in Arabidopsis thaliana (L) Heynh. Plant Physiol 112:327-336

Gaubier P, Raynal M, Hull G et al (1993) Two different Em-like genes are expressed in Arabidopsis thaliana seeds during maturation. Mol Gen Genet 8:409-418

Graeber K, Linkies A, Müller K et al (2010) Cross-species approaches to seed dormancy and germination: conservation and biodiversity of ABA-regulated mechanisms and the Brassicaceae DOG1 genes. Plant Mol Biol 3(1-2):67-87

Guan L, Zhao J, Scandalios JG (2000) Cis-elements and transfactors that regulate expression of the maize Catl antioxidant gene in response to ABA and osmotic stress: $\mathrm{H}_{2} \mathrm{O}_{2}$ is the likely intermediary signaling molecule for the response. Plant J 22:87-95

Hoffmann-Benning S, Kende H (1992) On the role of abscisic acid and gibberellin in the regulation of growth in rice. Plant Physiol 99:1156-1161

Hu YQ, Liu S, Yuan HM et al (2010) Functional comparison of catalase genes in the elimination of photorespiratory $\mathrm{H}_{2} \mathrm{O}_{2}$ using promoter- and 3'-untranslated region exchange experiments in the Arabidopsis cat 2 photorespiratory mutant. Plant Cell Environ 33:1656-1670

Koornneef M, Bentsink L, Hilhorst H (2009) Seed dormancy and germination. Curr Opin Plant Biol 5:33-36

Laloi C, Apel K, Danon A (2004) Reactive oxygen signaling: the latest news. Curr Opin Plant Biol 7:323-328

Langmead B, Trapnell C, Pop M et al (2009) Ultrafast and memory-efficient alignment of short DNA sequences to the human genome. Genome Biol 10:R25

Lefebvre V, North H, Frey A (2006) Functional analysis of Arabidopsis NCED6 and NCED9 genes indicates that ABA synthesized in the endosperm is involved in the induction of seed dormancy. Plant J 45:309-319

Liu ZQ, Yan L, Wu Z et al (2012) Cooperation of three WRKYdomain transcription factors WRKY18, WRKY40 and WRKY60 in repressing two ABA-responsive genes $\mathrm{ABI} 4$ and $\mathrm{ABI} 5$ in Arabidopsis. J Exp Bot 63(18):6371-6392

Margoliash E, Novogrodsky A, Schejter A (1960) Irreversible reaction of 3-amino-1-2-4-triazole and related inhibitors with the protein of catalase. Biochem J 74:339-348

Mhamdi A, Queval G, Chaouch S et al (2010) Catalase function in plants: a focus on Arabidopsis mutants as stress-mimic models. J Exp Bot 61:4197-4220

Miller G, Shulaev V, Mittler R (2008) Reactive oxygen signaling and abiotic stress. Plant Physiol 133:481-489 
Möller IM, Sweetlove LJ (2015) ROS signalling-specificity is required. Trends Plant Sci 2010 15(7): 370-374

Nambara E, Suzuki M, Abrams S et al (2002) A screen for genes that function in abscisic acid signaling in Arabidopsis thaliana. Genetics 161:1247-1255

Ogawa K, Iwabuchi M (2001) A mechanism for promoting the germination of Zinnia elegans seeds by hydrogen peroxide. Plant Cell Physiol 42:286-291

Park SY, Fung P, Nishimura N et al (2009) Abscisic acid inhibits type $2 \mathrm{C}$ protein phosphatases via the PYR/PYL family of START proteins. Science 324:1068-1071

Polidoros AN, Scandalios JG (1999) Role of hydrogen peroxide and different classes of antioxidants in the regulation of catalase and glutathione S-transferase gene expression in maize (Zea mays L.). Plant Physiol 106:112-120

Shang Y, Yan L, Liu ZQ et al (2010) The Mg-chelatase H subunit of Arabidopsis antagonizes a group of WRKY transcription repressors to relieve ABA-responsive genes of inhibition. Plant Cell 22:1909-1935

Smykowski A, Zimmermann P, Zentgraf U (2010) G-box binding factor reduces CATALASE2 expression and regulates the onset of leaf senescence in Arabidopsis. Plant Physiol 153:1321-1331

Tamura N, Yoshida T, Tanaka A et al (2006) Isolation and characterization of high temperature resistant germination mutants of Arabidopsis thaliana. Plant Cell Physiol 47:1081-1094

Torres MA, Dangl JL (2005) Functions of the respiratory burst oxidase in biotic interactions, abiotic stress and development. Curr Opin Plant Biol 8:397-403

Wallström SV, Aidemark M, Escobar MA et al (2012) An alternatively spliced domain of the NDC1 NAD $(\mathrm{P}) \mathrm{H}$ dehydrogenase gene strongly influences the expression of the ACTIN2 reference gene in Arabidopsis thaliana. Plant Sci 183:190-196

Wang M, van der Meulen RM, Visser K et al (1998) Effects of dormancy-breaking chemicals on ABA levels in barley grain embryos. Seed Sci Res 8:129-137

Wang YP, Li L, Ye TT et al (2013) The inhibitory effect of ABA on floral transition is mediated by ABI5 in Arabidopsis. J Exp Bot 64(2):675-684

Wei CL, Wu Q, Vega VB et al (2006) A global map of p53 transcription-factor binding sites in the human genome. Cell 124(1):207-219

Wu FQ, Xin Q, Cao Z et al (2009) The magnesium-chelatase H subunit binds abscisic acid and functions in abscisic acid signaling: new evidence in Arabidopsis. Plant Physiol 150:1940-1954

Yamaguchi S (2008) Gibberellin metabolism and its regulation. Annu Rev Plant Biol 59:225-251

Ye N, Zhu G, Liu Y et al (2012) Ascorbic acid and reactive oxygen species are involved in the inhibition of seed germination by abscisic acid in rice seeds. J Exp Bot 63:1809-1822

Zeevaart JAD, Creelman RA (1988) Metabolism and physiology of abscisic acid. Annu Rev Plant Physiol Plant Mol Biol 39:439-473

Zheng XM, Moriyama EN (2013) Comparative studies of differential gene calling using RNA-Seq data. BMC Bioinform 14(Suppl 13): $\mathrm{S} 7$

Zimmermann P, Heinlein C, Orendi G et al (2006) Senescence specific regulation of catalases in Arabidopsis thaliana (L.) Heynh. Plant Cell Environ 29:1049-1060 